\title{
Campamentos y defensa del territorio en el Egipto romano
}

\author{
Sabino Perea Yébenes \\ Universidad de Murcia
}

\begin{abstract}
RESUMEN ABSTRACT
Hacemos un repaso general a la guarnición romana en Egipto durante la época imperial, evaluando la importancia que tenían las tropas allí estacionadas en la defensa de la provincia, que se pone en relación con la estrategia imperial del llamado limes Arabicus. El número de tropas y los campamentos se adecuan en cada momento a las necesidades estratégicas y a las reformas políticoadministrativas que dividen provincias y cambian las fronteras interiores.

We do a general vision to the Roman garrison in Egypt during the imperial epoch, evaluating the importance that there had the troops there parked in the defense of the province, on which it puts in relation with the imperial strategy of the so called limes Arabicus. The number of troops and the camps are adapted in every moment to the strategic needs and to the political-administrative reforms that divide provinces and change the interior borders.
\end{abstract}

\section{PALABRAS CLAVE}

Egipto. Imperio romano. Ejército romano. Legiones. Auxiliares. Defensa del territorio. Campamentos. Frontera.

\section{KEY WORDS}

Egypt. Roman Empire. Roman Army. Legions. Auxilia. Defence. Territory. Forts. Limes.

Como se sabe, Egipto es una provincia excepcional en muchos sentidos para el estudio del ejército romano. A efectos de documentación, Egipto ha dado tan grande número de papiros militares ${ }^{1}$ que quizás en esta provincia, mejor que en

1 S. DARIS, Documenti per la storia dell' esercito romano in Egitto, Milán 1964. R.O. FINK, Roman Military Records on Papyrus Cleveland 1971, passim. S. DARIS, «Documenti minori dell' esercito romano in Egitto», ANRW II.10.1 (1988) 724-742. 
ninguna otra, pueden seguirse muchos aspectos de la vida cotidiana de los soldados $^{2}$. Un banco de datos comparable en su conjunto puede ser, para la frontera británica, el excepcional hallazgo de las tabillas del fuerte de Vindolanda ${ }^{3}$.Otra particularidad de Egipto, desde los albores de su milenaria cultura, es el determinismo geográfico, el aislamiento que delimita el país por los cuatro costados. Esta circunstancia importa mucho a la hora de comprender el despliegue de fuerzas militares y la estrategia defensiva. Desde tiempos inmemoriales hasta la actualidad la vida de Egipto se articula en torno a las aldeas agrícolas que escoltan al Nilo en su avance hacia el mar. En la zona del Delta se dará la mayor densidad de población. Allí, en la costa, tendrá su punto de comunicación más importante hacia Roma y el resto de los territorios del Imperio, es decir, Alejandría. Y, por tierra, la vía de comunicación con las provincias vecinas es el desierto oriental del Delta, cruzando la franja norte del Sinaí hacia Palestina y Siria. Durante la época romana imperial, y desde el punto de vista militar, estos territorios -Egipto, Siria, Judea ${ }^{4}$, con sus variaciones de fronteras - han de percibirse como un conjunto, como una «zona militar ${ }^{5}$, la oriental, de fuerzas desplazadas y compensadas ${ }^{6}$, para guarnecer la frontera terrestre suroriental romana, entre Antioquía y Alejandría.

Para conocer la distribución de tropas en Egipto, hay que distinguir desde el principio y con claridad dos épocas:

1. La altoimperial, desde la incorporación al Imperio por parte de Augusto del reino griego de Egipto ${ }^{7}$, hasta el reinado de Diocleciano. En estos tres siglos la

2 G.R. WATSON, The Roman Soldier, London 1960. R.W. Davies, «The Daily Life of the Roman Soldier», ANRW, II,1, Berlin/NY 1974, 299-388. R. W. DAVIES, Service in the Roman Army (edited by D. BREEZE and V. MAXFIELD), Edinburgh 1989. J.M. CARRIÉ, «El soldado romano», en A. GIARDINA (ed.), El hombre romano, Madrid 1991, 121-160. En particular para Egipto: S. DARIS, «Documenti minori», 724742.

3 Sobre estos documentos, remito, obviamente, a la edición de los mismos, en varios volúmenes, debidos a A.K. Bowman: Roman Writing-Tablets from Vindolanda, London 1981 ss. Id., Life and letters on the Roman frontier. Vindolanda and its people, London 1994. A.K.BowmAN, J.D.THOMAS Vindolanda: the Latin writing-tablets. Britannia Monograph 4, London 1983. Sobre el fuerte-campamento y la exploración arqueológica: R.E. BIRLEY, Vindolanda. A Roman frontier post on Hadrian's Wall. London 1977. Id., The Roman documents from Vindolanda, Newcastle upon Tyne 1990. A.K. BowmAN, «El ejército imperial romano: las cartas y la cultura escrita en la frontera septentrional», en A. K. BowmAN, G. D. Woolf, Cultura escrita y poder en el Mundo Antiguo, Barcelona 2000, 173-197 y 355-357.

4 Y Arabia a partir de 106, con la anexión de la Nabatea. Sobre la guarnición romana en Arabia: M.P. SPEIDEL, «The roman Army in Arabia», ANRW, II,8, 1977, 687-730; J. TEIXIDOR, ALes Nabatéens du Sinaï» en: D. Valbelle, C. Bonnet (eds.), Le Sinaï durant l' Antiquité et le Moyen Âge. 4000 ans d' Histoire pour un désert, Paris 1998, 83-87.

5 Antes del año 106 las tropas asentadas en la región son, según D. KenNEDY, The Roman Army in Jordan, Londres, 2000, 40:

a) En Siria, tres legiones: la VI Ferrata (¿con sede en Samosata?), la IV Scythica, con sede en Zeugma, y la III Gallica, (¿con sede en Raphanea?); más 8 alas (aprox.) y 19 cohortes (aprox.)

b) En Judea: una legión: la X Fretensis, en Jerusalén; más 2 alas y 12 cohortes.

c) Egipto: dos legiones: la III Cyrenaica (en Alejandría) y la XXII Deiotariana.

6 O como propone Pollard a modo de «informal interaction», vid. N. PoLLARD, Soldiers, Cities, \& Civilian in Roman Syria, Michigan 2000, 111-151.

7 Res gestae, 27, 1: Aegyptum imperio populi Romani adieci. Como es bien sabido, Egipto gozó de un estatuto singular entre las provincias romana bajo Augusto, que pareció tomarla bajo su especial cuidado (cf. Tac. Ann. II, 59, 4), confiando el gobierno a un funcionario ecuestre (a un prefecto imperial), y 
guarnición de Egipto tiene pocas variaciones, y se mantiene regularmente su red de campamentos y de stationes, así como el número de soldados.

2. La bajoimperial, concretamente desde 283 hasta el final del siglo IV. La división provincial dioclecianea conlleva un nuevo concepto de defensa, de fijación de fronteras y de organización de las tropas. Esta «revolución de Diocleciano» afectó particularmente a Egipto, o, mejor, a una parte de Egipto, la defensa del Istmo de Suez y la seguridad de las rutas caravaneras que conectaban con Petra y Bostra $^{8}$. Desde aquí salen dos ramales: uno hacia el desierto oriental, hacia Palmira y Dura Europos, y otro hacia el norte, hacia Sweida, Filadelphia (actual Ammán), Damasco, Alepo y Antioquía.

\section{ALTO IMPERIO}

Se ha estimado que para los tres primeros siglos del Imperio, la guarnición de Egipto la formaban apenas 20.000 ó 23.000 soldados $^{9}$.

Con Augusto, a partir del año 30 a. C., quedan estacionadas tres legiones en Egipto $^{10}$ : la III Cyrenaica ${ }^{11}$, la XXII Deiotariana ${ }^{12}$ y una tercera cuyo nombre se desconoce, quizás la XII (Fulminata). Esta última sale de Egipto poco después del año 6 según algunos autores ${ }^{13}$ o ya en época de Tiberio, para consolidar la hegemonía militar en la recién conquistada Siria, guarneciéndola con tres legiones. Las otras dos quedaron instaladas en Nicopolis, en el Delta, a cinco kilómetros al este de Alejandría. En el año 63 vino a sumarse la XV Apollinaris ${ }^{14}$. Esta legión venía de lu-

dando a la provincia ese mismo rango, nombrado a finales del año 30 o comienzos del 29 a. C. Sobre los fasti de estos gobernadores ecuestres remito a: P. BURETH, «Le préfet d' Égypte (30 a.v. J.-C. - 297 ap. J.-C). État présent de la documentation en 1973» ANRW II, 10, 1, 1988, 472-502. Completar con G. BASTIANINI, «ll prefetto d' Egitto (30 a. C. - 297 d. C.). Addenda (1973-1985)» ANRW II, 10, 1, 1988, 503-517. Este prefecto era también el jefe del ejército. Naturalmente, cuando el emperador visitaba la provincia actuaba como comandante supremo. Eso, no obstante, sucedía muy poco: para los primeros siglos sólo se atestiguan las visitas de seis emperadores: Vespasiano en 69, Tito en 71, Hadriano en el invierno de130-131, Marco Aurelio en 176, Septimio Severo en 194, y Caracalla en 215-216. Dudosa es la estancia de Antonino Pío. M. SARTRE, «L'empereur, le préfet, la province», en: VV. AA, Égypte Romaine. L' Autre Égypte, Marseille 1997, 41-42 y 46.

${ }^{8}$ Cfr. M. ReddÉ, / T. Baouzou, «Pistes caravanières de Syrie, d' Arabie et d'Égypte: Quelques éléments de comparison", en: T. FAHD (ed.), L'Arabie préislamique et son environnement historique et culturel. Actes du Colloque de Strasbourg 24-27 juin 1987. Leiden 1989, 485-497.

9 M. SARTRE, El Oriente romano. Provincias y sociedades provinciales del Mediterráneo oriental, de Augusto a los Severos (31 a. C. - 235 d. C.), Madrid 1994, 460.

10 M. P. SPEIDEL, «Augustus' Deployment of the Legions in Egypt», Chron. d'Égypte 47, 1982, 120-124 = Roman Army Studies I. Amsterdam, 317-322.

11 C. WolfF, «La legio III Cyrenaica au ler siècle», en Y. LE BOHEC / C. WolfF (eds.), Les légiosn de Rome sous le Haut-Empire, Lyon 2000, 339-340. Para la historia de la legión en el siglo I d. C.: J. RoDRÍGUEZ GonZÁLEZ, Historia de las legiones romanas, Madrid 2001, vol. I, 132-134.

12 S. DarIS, "Legio XXII Diotariana», en Y. Le BoHEC / C. WolfF (eds.), Les légiosn de Rome sous le Haut-Empire, Lyon 2000, 365-367; J. RodRíGUEz GonzÁLEZ, Historia de las legiones romanas, vol. I, 411 414.

13 H.M.D. PARKER, The Roman Legions, Oxford 1928 (reimpresión Cambridge, 1958), 128.

14 Flav. Ios. Bell. lud. III 3 [III 65]. 
char en la guerra pártica de los años 58-63 y llegó al puerto de Alejandría para reforzar la guarnición de Egipto durante cuatro años hasta que pasó a Judea para combatir la primera Gran Rebelión judía ${ }^{15}$. Este movimiento táctico indica una tendencia que se confirmaría las décadas siguientes: utilizar a las legiones de Egipto para combatir en los frentes de guerra abiertos más al oriente, particularmente en Arabia y Judea.

Así lo vemos en Petra, capital del vecino reino nabateo, tomada por destacamentos de la legión III Cyrenaica ${ }^{16}$, en el año 106. Se conservan inscripciones con su nombre en el siq o desfiladero que conduce a la ciudad de Petra. Poco después, en 123 toda la legión III Cyrenaica es trasladada a Bostra, la capital de Arabia $^{17}$ (al sur de la Jordania actual). Hacia 135 la legión XXII Deiotariana sale de Egipto para no regresar jamás ${ }^{18}$.

Legiones romanas en Egipto (Alto Imperio)

En todos los casos, el campamento-sede: Nicópolis, a $5 \mathrm{~km}$ de Alejandría

\begin{tabular}{l|c|c|c|c|c}
\hline Fechas & $\begin{array}{c}30 \text { a. C. }-6 \text { d. C. } \\
\text { (o bajo Tiberio) }\end{array}$ & 30 a. C. -123 d.C & 30 a. C. -123 d. C. & 63 d. C. -66 d. C. & $\begin{array}{c}127 \text { d. C. }- \text { final } \\
\text { del s. V d. C. }\end{array}$ \\
\hline $\begin{array}{l}30 \text { a. C. }- \\
6 \text { d. C (o bajo } \\
\text { Tiberio) }\end{array}$ & $\begin{array}{c}\text { LEG. XII } \\
\text { (Fulminata) } \\
\text { [Trasladada } \\
\text { a Siria] }\end{array}$ & $\begin{array}{c}\text { LEG. III } \\
\text { CYRENAICA }\end{array}$ & $\begin{array}{c}\text { LEG. XXII } \\
\text { DEIOTARIANA }\end{array}$ & & \\
\hline 63 d. C. - \\
66 d. C
\end{tabular}

${ }^{15}$ Flav. Ios. Bell. Iud. III 3 [III 65]; Tac. Hist. V 1.

16 P.-L. GAtieR, «Le legio III Cyrenaica et l’ Arabie», en Y. Le Bohec / C. Wolff (eds.), Les légiosn de Rome sous le Haut-Empire, Lyon 2000, 341-349.

17 G.W. BowERSOck, «A Report on Arabia Provincia», JRS 61, 1971, 232.

18 En realidad se pierde el rastro en Egipto de esta legión desde agosto del año 119, fecha en que hay un documento fechado que certifica su estancia en Nicopolis junto a la III Cyrenaica (BGU I, $140=\mathrm{J}$.H. OLIVER, Greek Constitutions of the Earky Roman Emperors from Inscriptions and Papyri, Philadelphia 1989, n1 70), aunque tal ausencia se debió posiblemente a su remoción a Palestina, donde actuaría en la represión de la Segunda Guerra Judía, en 132-135 (en tal sentido, L. KEPPIE, «The Legionary Garrison of Judaea under Hadrian», Latomus 32 (4), 1973, 814; B. ISAAC / I. RoLL, «Judaea in the Early Years of Hadrian's Reign», Latomus 38 (1), 1979, 59; S. Applebaum, Prolegomena to the Study of the Second Kewish Revolt (A.D. 132-135), Londres 1976, 26, 36, 45, 62), siendo este su final, por licenciamiento o derrota (cfr. M. Mor, Two Legions - the same Fate? «(The Disappereance of the Legions IX Hispana and XXII Deiotariana)», ZPE, 62, 1986, 267-278). Discusión sobre estas posibilidades, en S. DARIS, «Legio XXII Diotariana», 365 y nn. 4-6. 
A la desguarnecida provincia de Egipto llegó entonces la II Traiana ${ }^{19}$, la única unidad legionaria acantonada en esa provincia hasta el imperio de Diocleciano, y aún después.

\section{Las legiones «Aegipcias» en acción}

\section{Legio XXII Deiotariana}

Junto a su legión compañera alejandrina, la III Cyrenaica, realizó desde su instalación en Egipto, la función de prevención estratégica (rechazar los intentos de invasión por tierra desde Asia, así como la vigilancia del puerto de Alejandría), y también misiones de vigilancia policial sobre el tráfico comercial y el traslado de mercancías fundamentales para los habitantes de Egipto y para Roma. A medida que los más veteranos de estas legiones fueron pasando al retiro de la vida civil, posiblemente como campesinos en el fértil valle del Nilo, se hicieron, como es natural, nuevos reclutamientos. Muchos de los nuevos legionarios procedían del propio país, y otros de las provincias orientales, al menos para el siglo । d. C. Esta circunstancia de los origines quizás influyó en difundir la opinión de que las legiones egipcias eran poco aguerridas (lo cual es cierto si las comparamos con los aguerridos legionarios del limes norte, habituados a fortiori a un clima más inclemente y al hecho de estar en continuo pie de guerra), pero esa fama, quizás injusta, no les eximió de participar en guerras que de algún modo les afectaba, por proximidad o por intereses estratégicos regionales: así, vemos participar a un destacamento de esta legión en Armenia, en la guerra que Corbulón mantenía contra los partos (entre 58 y 63). Y muy pronto, en el 66, intervendría en Egipto en graves problemas de orden público provocados por los judíos de Alejandría ${ }^{20}$. El «problema judío» parece que iba a ser «el verdadero problema de esta legión», cuyo destino parecía estar abocado a combatir contra ellos. Poco después las dos legiones egipcias se sumaron al asedio de Jerusalén que mantuvieron las tropas romanas y un grupo de reyes aliados contra los rebeldes judíos. Las legiones estaban mandadas por el C. Liternius Fronto, el praefectus castrorum de ambas legiones con un mando especial para la ocasión, y el título de praepositus. Al frente de la expeditio aegyptiaca estaba, naturalmente, el praefectus de la provincia, el rico e influyente alejandrino Ti. Iulius Alexander, amigo personal de Vespasiano y de Tito. Junto a ellos estaba durante el asedio de Jerusalén, y también sus legiones $^{21}$. Flavio Josefo destaca el valor de los artilleros y alaba la oportunidad y la

19 Sobre los documentos y presencia de esta legión en Egipto, S. DARIS, «Legio /I Traiana Fortis», en Y. LE BOHEC / C. WolfF (eds.), Les légiosn de Rome sous le Haut-Empire, Lyon 2000, 359-363. Fundamental sobre la historia de esta legión: J. RodríGuez GonzÁLEZ, Historia de las legiones romanas, vol. I, 107-112.

20 Fl. los. Bell. lud. II 21 [II 494]

${ }^{21} \mathrm{FI}$. Ios. Bell. Iud. VI 1 (V 44); VII 9 (VI 238); Tac. Ann. XV 26, 2; Tac. Hist. V 1, 2. 
eficacia de las máquinas de guerra utilizadas por los hombres de la legio III Cyrenaica ${ }^{22}$.

Las evoluciones de esta legión durante la guerra civil del 69 está ligada al destino de Vespasiano, a quien juró fidelidad. Un destacamento marchó a Siria, para unirse a las tropas que mandaba Licinio Muciano, otro amigo incondicional de Vespasiano, y verdadero homo fortis de oriente en su condición de comandante de las poderosas legiones sirias. Desde la capital siria, Antioquía, la expedición partió para Italia a defender los "opción» de Vespasiano ${ }^{23}$, una apuesta acertada pues fue el vencedor del conflicto, y emperador.

Una inscripción del año 84 informa de labores policiales de vexillationes de esta legión en la milenaria ciudad de $\operatorname{Tebas}^{24}$ en misión de vigilancia de fronteras y evitar la incursión de tribus nómadas y los asaltos a las caravanas que buscaban los puertos egipcios de Myos Hormos o de Berenice en la costa egipcia del Mar $\mathrm{Rojo}^{25}$. Estas patrullas legionarias, de la XXII y de la III Cyrenaica, vendrían a reforzar las misiones policiales de las tropas de auxiliares en el curso alto del Nilo. Con el mismo propósito se atestigua su presencia en los puestos avanzados de Talmis y de Pselcis en tiempos de Trajano. Éste trasladó esta legión al frente parto en 114-117; puede que en 123 o 127 fuese llevada a Judea en lugar de II Traiana. Poco después y antes del final del reinado de Hadriano se pierde su pista. Se ha apuntado la posibilidad de que, durante la represión de la revuelta judía de $132-135$, fue destruida en una emboscada o disuelta ${ }^{26}$. En todo caso, un final poco honroso para un águila romana.

\section{Leg. III Cyrenaica}

Parece que en un primer momento (entre el 30 a. C. y el 26/25 a. C.) la legión actuó en Tebas y Coptos, aunque con toda probabilidad tenía el campamento base en Babilonia, una población en el vértice del Delta. En fecha indeterminada (quizás alrededor de 5 a. C. y como mucho en 43) ${ }^{27}$ cambió su acantonamiento permanente desde el sur de la provincia al norte de la misma, a Nicopolis. Muy pronto,

22 Fl. los. Bell. lud. VI 7 [V 287].

23 Tac. Hist. III 46, 2; FI. los. Bell. Iud. V 13 [IV 632].

24 CIL III 30, 36.

25 M. REDdÉ, / J.-C. Golvin, «Du Nil à la Mer Rouge: documents anciens et nouveaux sur les routes du désert oriental d' Égypte», Karthago 21, 1987, 5-64. A. BüLow-JAcomsen / H. Cuvigny / J.L. FouRnET, «The identification of Myos Hormos: New Papyrological Evidence», BIFAO 94, 1994, 27-42; H. CuVIGNY, (ed.) [Avec la collaboration de J.-P. Brun, A. Bülow-Jacobsen, D. Cardon, J.-L. Fournet, M. Leguilloux, M.-A. Matelly, M. Reddé], La route de Myos Hormos. L'armée romaine dans le désert oriental d' Égypte. Praesidia du désert de Bérénice I. (Institut français d'archéologie orientale; Fouilles de l'IFAO 48/1, 2003). 2 vols.

${ }^{26}$ CIG 4.724. En opinión de M. GICHON, 1979, 89, la emboscada fue en la llanura de ludaea, cuando, camino del frente, atravesaba un paraje denominado Kefar Hambla y los rebeldes habrían destruido a continuación la mayoría de los emblemas de la legión, excepto los necesarios para probar su victoria.

27 J. Rodríguez GonzÁlez, Historia de las legiones romanas, vol. I, pp. 132-133. 
pues, compartiría misiones, oficiales ${ }^{28}$, y destinos con la legión XXII Deiotariana, que ya estaba acuartelada en el lugar. Una de sus misiones principales era controlar las rutas entre el Nilo y el sinus Arabicus, por tanto vigilancia interior por la cuenca nilótica, de norte a sur, y los ramales que conducían al Mar Rojo, sin descuidar las fronteras meridionales y las razzias de nómadas.

Participó en las campañas orientales de Corbulón contra los partos en Armenia, y Capadocia, y más tarde con la XXII Deiotarana se sumó al contingente que tuvo como punto final la destrucción del Templo de Jerusalén. Junto a esta legión juraron fidelidad a Vespasiano en el campamento de Nicopolis el 1 de julio del 69, y marcharon a Siria a unirse al ejército de Muciano en Siria, para marchar a Italia. Era, pues, también, una legión del «régimen flavio».

De vuelta a Egipto parece que entre el 80 y el 91 unos destacamentos reocuparon temporalmente las primitivas guarniciones de Tebas y $\operatorname{Coptos}^{29}$; y más tarde otro destacamento se documenta en Talmis ${ }^{30}$.

En la ciudad de Petra (capital del antiguo reino nabateo) quedan varios testimonios de la legión III Cyrenaica a partir del año 106. En ese año Trajano sumó esta legión a los efectivos sirios mandados por A. Cornelio Palma Frontoniano, que conquistó Petra para Trajano. La Nabatea se integró al Imperio con el nombre de Arabia Petrea. Al sur de la nueva provincia quedaron destacamentos de la provincia, siendo sus hombres - quizás junto a los de la legión VI Ferrata, ésta en todo caso con menor impronta en la región- quienes formaron la primera guarnición de Bostra $^{31}$, una plaza fuerte estratégica de suma importancia militar y estratégica, importancia que se sustancia con la construcción, con mano de obra e ingeniería legionaria, de la via nova Traiana, entre el Mar Rojo y la frontera de Siria.

En Egipto, en el año 117, algo más de la mitad de esta legión, unos tres mil hombres, participaron bajo las órdenes de Marcio Turbo en la represión de los judíos en las provincias de Egipto (en Alejandría) y de Cirenaica (en Cirene) ${ }^{32}$. De sus cuarteles egipcios vuelve a salir, junto a la legión «hermana», la II Traiana, para acompañar a Hadriano a la frontera del Éufrates, donde se barruntaban vientos de guerra con los partos. Parece que entre los años 119 y 127 ambas legiones tenían un mando único. Con la finalidad de fortalecer el frente más oriental, hacia el año 130 Hadriano traslada definitivamente la unidad a Bostra. Eso, naturalmente, no impedía que la legión actuase, como lo había hecho desde entonces

28 Principalmente el puesto de prafectus castrorum, que en Egipto, provincia de rango ecuestre, tiene gran predicamento.

29 CIL III 34.

30 J. LeSQUIER, 1918, 61, 471.

31 P. FreEman, 1996, 9599.

32 Para los acontecimientos en Cirenaica: L. GASPERINI, 2003, 155171. Para las demás revueltas orientales: S. PEREA YÉBENES, «Aspectos políticos y religiosos de las revueltas judías en época de Trajano, en Egipto, Chipre y Mesopotamia», en S. Perea Yébenes, Entre Occidente y Oriente. Temas de historia romana: aspectos religiosos, Madrid 2001, 315-333; ID., «Los últimos años de Trajano y los judíos de Oriente», en J. Alvar / J.M. Blázquez, eds., Trajano, Madrid 2003, 173-187. 
desde su base egipcia, saliera para actuar en puntos o conflictos estratégicos de la zona oriental, como sucedió poco después, en 132-135, en la sofocación de la revuelta judía de Bar-Kochba.

\section{Leg. II Traiana}

Mucho de lo dicho antes de la legión III Cyrenaica vale para su «gemela egipcia» II Traiana a partir del año desde el año 109, que es el momento más probable de su creación por Trajano ${ }^{33}$ en Mesia Inferior. Pronto fue trasladada a Siria, y en 117 se atestigua en Judea ${ }^{34}$, en su capital administrativa, Cesarea Marítima. En 123 coincide en Antioquía con la III Cyrenaica, una legión de Egipto que operaba temporalmente en esta región. Junto a esta legión regresará la II Traiana a Egipto, acuartelándose ambas en Nicópolis, y facilitando la salida de la XXII Deiotariana.

A partir de tiempos de Hadriano la II Traiana va a ser la única guarnición legionaria en Egipto. Su acción no se limita al apoyo de acciones en eventuales episodios bélicos exteriores sino también la vigilancia policial de la provincia de Egipto, tal como demuestran los testimonios epigráficos y papiráceos que nos informan de la presencia de destacamentos de la legión en el Alto Nilo, en Tebas y en Nubia $^{35}$. En el vértice del Delta, se documenta en el campamento de Babilonia, y en la vieja ciudad de Menfis ${ }^{36}$, sin descuidar las labores de policía en la metrópolis, Alejandría. A la ciudad llegaba en el año 130 el emperador Hadriano, y seguramente fue inspeccionada por éste. Una evaluación favorable, y su posición y orientación estratégica natural hacia el oriente, hizo que fuera llamada por Hadriano para sofocar la revuelta judía de 132. Tomada Jerusalén y sometida Judea, la legión volvió a su provincia, Egipto.

La legión tenía cierta mala fama de «poco aguerrida», quizás por el hecho de que casi todos sus hombres eran egipcios a partir de mediados del siglo II. La prosopografía ha demostrado ${ }^{37}$ que aproximadamente la mitad de ellos era de origen egipcio $^{38}$, y que buena parte del resto procedían de las provincias circundantes. En el siglo II la aportación del elemento africano es ya estructural, como indica la relación de origines de una monumental inscripción de Nicopolis de Egipto con 134 nombres de soldados y sus lugares de nacimiento ${ }^{39}$, esctritos en los laterales del ara y en la cara posterior (FIGURA).

${ }^{33}$ Cass. Dio LV 24, 3. CIL III 79, donde aparece ya con el apelativo fortis.

34 CIL X 3733 (= ILS 2083); AE 1979, 628;

35 CIL III 42.

36 CIL III 141476.

37 R. CAVEnAILlE, «Prosopographie de l' armée romaine d' Égypte d' Auguste à Dioclètien», Aegyptus 50, 1970, 213-320. Completar con N. CRINITI, «Supplemento alla prosopographie de l' armée romaine d' Égypte d' Auguste à Dioclètien», Aegyptus 53, 1973, 93-158.

38 J. LesquiER, L'armée romaine d'Égypte d'Auguste à Diocétien. El Cairo 1918, 2 vols. 1918, p. 210 y 214.

39 Sobre este documento excepcional, G. ForNI, «La base eretta a Nicopoli in onore di Antonino Pio dai Veterni della legione II Traiana», en Studi di Storia Antica in Memoria di L. de Regibus, Génova 1969, 


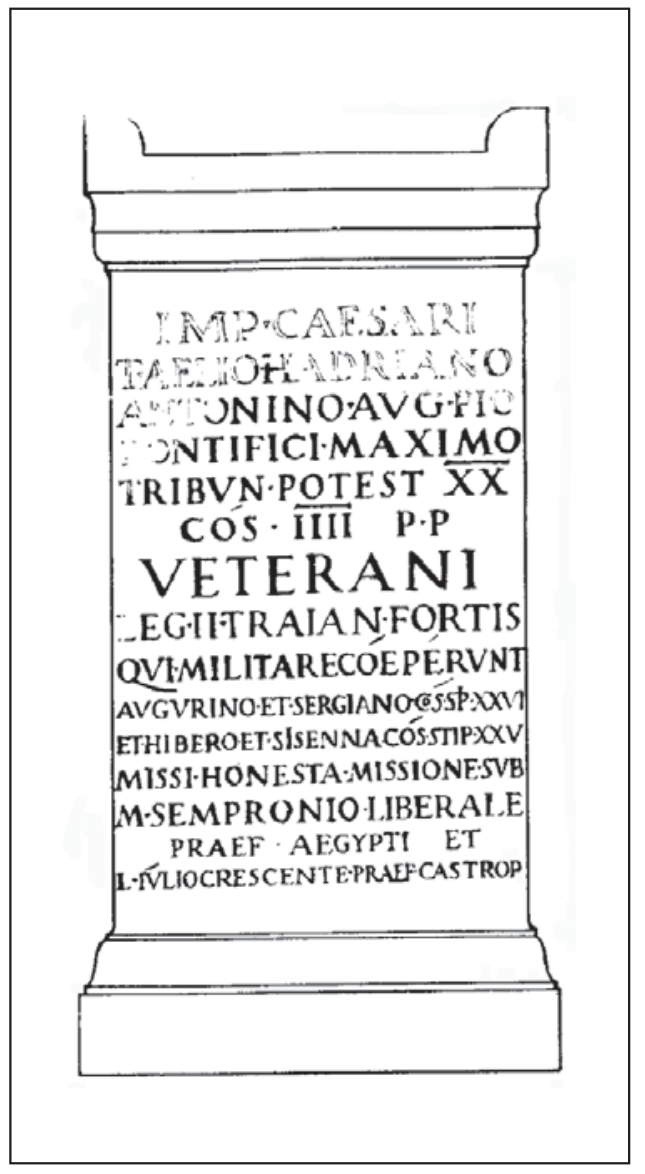

Aproximadamente la mitad de los soldados de las legiones de Egipto procedían de las provincias norteafricanas; y otro gran número de las provincias de oriente. Esa circunstancia favorecía la labor policial en el país, por su conocimiento de la lengua y del territorio, aunque su reputación menguaba en los escenarios más duros del Imperio, en las fronteras. $Y$ allí interviene puntualmente (o algunos destacamentos suyos), en el frente parto, en los años 163 y 166, en el ejército de Lucio Vero. Pocos años después es trasladada a Italia, luego a Dalmacia ${ }^{40}$, y quizás actúa en $R a-$ etia y el Nórico.

La ausencia de toda o gran parte de la legión de tierras de Egipto, debilitó la presencia militar disuasoria, facilitó la llamada «revolución de los boyeros", los boukoloi del Delta, que tuvieron que ser reprimidos con tropas llegadas desde Siria. A su mando estaba el todopoderoso vir militaris Avidio Casio, rector totius Oriens. Pocos años después, en 175, Casio intentó conseguir el poder imperial con un golpe de

177-210 (= G. ForNI, Esercito e marina di Roma antica, Raccolta di contributi, Stuttgart 1992, $142-$ 179); F. KAYSER, Recueil des inscriptions grecques et latines (non funéraires) d'Alexandrie impériale (I.er - III. ${ }^{e}$ s. apr. J.-C), El Cairo 1994, n1 102. Estos soldados que sirven en la legión II Traiana en el segundo cuarto del siglo II d. C. vienen de sitios muy diversos: de AFRICA: 1 de Acholla, 2 de Ammaedera, 1 de Assuras, 1 de Bararus, 34 de Carthago, 1 de Cirta, 1 de Cuicul, 3 de Hadrumetum, 4 de Lepcis Magna, 8 de Lepcis Minus, 1 de Maxulla, 1 de Melzi, 1 de Oea, 1 de Thaenae, 2 de Thamb(?), 1 de Theveste, 1 de Tuburbo Minus, 1 de Thuburbo Maius, 5 de Thysdrus, 3 de Uthina, 15 Utica. De ITALIA: 1 de Abella o Abellinum, 1 de Ameria, 1 de Blera, 1 de Brixellum, 1 de Iguvium, 2 de Neapolis, 1 de Nuceria, 1 de Perusa, 1 de Pisa, 3 de Roma, 1 de Sora, 1 de Sutrium. De DALMATIA: 1 de Varvaria. De GERMANIA INFERIOR: 1 de Ara (Colonia). De ASIA MENOR: 1 de Amisus, 1 de Anazarbus, 1 de Nicomedia, 1 de Perge, 1 de Prusias, 1 de Tavium. De SIRIA-FENICIA: 2 de Antioquía, 1 de Apamea, 1 de Ascalon, 2 de Berytus, 3 de Cesarea, 2 de Currhus, 2 de Epiphaneia, 1 de Gabala, 1 de Gabara, 1 de Laodicea, 1 de Larissa, 1 de Sebaste. De EGIPTO: 1 de Ptolemais.

La citada inscripción tiene un «paralelo» más tardío: la dedicación hecha a Septimio Severo por los veteranos de la misma legión II Traiana (vid. F. KAYSER, n1 105). Se conservan 40 nombres con sus respectivas menciones de origo. Estos hombres, que entraron a servir en 168 fueron reclutados principalmente en Egipto (de Alexandría, de Paraetonium, de Tanism de Tebas, y un gran número de «origines castris». Solo 8 no son de procedencia egipcia, y vienen de Siria (Cesarea, Antioquía, Samosata, Hierápolis, Filadelfia), África (Cartago, Hadrumeto), y Bitinia (Nicomedia).

Por otra pare sabemos que el reclutamiento de los soldados de la legión III Augusta, muy bien estudiado, demuestra igualmente el espectacular progreso de la aportación del elemento africano a esta legión con el correr de los primeros siglos del Imperio. Y. LE BOHEC, La Troisième Légion Auguste, 495-502. En el periodo 117-161 se constatan epigráficamente 166 soldados de origen africano (y 115 extranjeros), y en el periodo 193-238 los africanos son 501 (casi triplica la cifra anterior) y los extranjeros 24, dividiendo por más de cuatro veces su presencia en esta legión para este periodo. No ha de pasar inadvertido que esta fortísima presencia de africanos en la III Augusta se produce durante la dinastía severiana, sobre todo a partir su fundador Septimio Severo, igualmente africano.

40 CIL III 1980 (= ILS 2287). 
mano. Y tuvo el apoyo, entre otras, de la II Traiana en abril y mayo del 175. La derrota de Casio no tuvo graves consecuencias para la legión ni para el gobernador de Egipto, C. Calvisio Estaciano, que fue condenado al exilio a una isla, salvando la vida pero no la dignidad ${ }^{41}$. La visita de Marco Aurelio a Egipto en 176 no tuvo, por lo que sabemos, repercusiones negativas para la legión II Traiana, a pesar de su posicionamiento en el bando de Casio. En la decisión de «non decimatio» debió actuar, a favor de la legión, el hecho de su presencia al lado de Marco Aurelio en el frente danubiano uno años antes.

La legión, o mejor sus mandos, es decir los prefectos de la provincia y sus altos oficiales, parecían estar abocados a jugar siempre a bando perdedor en las guerras por el trono imperial. Así sucedió tras la muerte de Cómodo y la guerra civil desatada por los aspirantes. La legión de Egipto apostó por Pescenio Nigro, «un hombre de la casa», pues había sido su comandante máximo en calidad de praefectus castrorum. Pero de nuevo apostó a caballo perdedor, pues Nigro fue derrotado por Septimio Severo, comandante de las legiones danubianas y legado de Panonia Superior. Severo ocuparía el trono de Roma y su dinastía gobernó el imperio durante unos cuarenta años. De nuevo el emperador vencedor no podía permitirse el lujo de licenciar a una legión por haber apostado por otro general aspirante al trono. La política, siempre inteligente, de Severo, recondujo la situación, y para ganarse la fidelidad de las tropas egipcias ${ }^{42}$, llamó a la legión II Traiana a luchar a su lado en el frente parto.

La presencia de la II Traiana fuera de Egipto se hace más frecuente durante el reinado de los Severos, haciendo el doble papel de defensa del territorio egipcio y defensa de las fronteras del imperio. Durante los próximos decenios, la acción de la legión parece multiplicarse en escenarios distintos y distantes - ¿o acaso debemos pensar en diversos destacamentos de la misma?-, pues está atestiguada en Raetia en el año 213 reforzando el ejército de Caracalla en su guerra contra los alamanes ${ }^{43}$. Al lado del emperador, o mejor en defensa de su causa política, la II Traiana actúa con mano dura contra los amotinados alejandrinos que protestaban con razón contra las arbitrariedades de Caracalla ${ }^{44}$.

Durante el reinado de Alejandro Severo, la legión combate en el frente parto, en Mesopotamia, en 231-232 ${ }^{45}$.

41 Cass. Dio LXXII 28, 3.

42 No hay noticias de represión o algo por el estilo en la visita de Septimio Severo a Egipto, en 199200, y la supuesta revista de las tropas legionarias de la provincia (cf. Cass. Dio LXXVI 13).

43 CIL III 14.1382; AE 1892, 47; 1893, 125.

44 Sobre los acontecimientos del 214, Historia Augusta, Ant. Caracalla 6, 23: «... se dirigió a Alejandría, convocó al pueblo en el gimnasio y le llenó de reproches. Ordenó que se hiciera una leva de hombres fuertes para empuñar las armas, pero inmediatamente acabó con los elegidos, siguiendo el ejemplo de Ptolomeo Evergetes, el octavo que llevaba ese nombre. Además, tras dar señal a los soldados, para que asesinaran a sus huéspedes, provocó una gran matanza en la ciudad de Alejandría».

45 R. Alston, Soldier and Society, 72. 
En tiempos de la llamada «anarquía militar» las actuaciones de esta legión son menos conocidas ${ }^{46}$, aunque en la misma tónica anterior: vigilancia policial interior y acciones bélicas puntuales en el exterior. Entre las primeras cabe recordar la escolta de la persona y de la comitiva del corrector Ulpio Pasión, en viaje de servicio por el país del $\mathrm{Nilo}^{47}$; en el ámbito exterior, parece que vexillationes de esta legión viajaron desde Egipto a la Galia y a Britania para acciones puntuales. Los años 60 y 70 del siglo III la historia de la II Traiana está condicionada por la política oriental, sucumbiendo al encanto y a la política de la reina rebelde Zenobia de Palmira. Ésta se apoderó de las provincias del Oriente romano, sometiendo a sus guarniciones, entre ellas las de Egipto, si bien en 271 volvió a la disciplina romana por mano de Marco Aurelio Probo ${ }^{48}$ (el futuro emperador Probo) ahora a las órdenes de Aureliano, que visitó el país del Nilo en 273. Las guerras y conquistas de Aureliano vienen justificadas en capítulo 32 de la Vita Aureliani que podemos leer en la Historia Augusta: tras mantener guerras victoriosas en Tracia, en Egipto sofocó la revuelta de Firmo, que había pretendido hacer de la provincia un Estado independiente. Recuperó Egipto para Roma, y combatió a Tétrico en las Galias; y sobre todo había pacificado el Oriente sometiendo a la reina Zenobia. De vuelta a Roma, este «príncipe de Oriente y Occidente» celebró su triunfo en el año 274 (hoc est de oriente et occidente, triumphum Romanis oculis exhiberet) ${ }^{49}$.

\section{$A U X I L I A$}

La legiones eran complementadas, con alas y cohortes auxiliares. En tiempos de Augusto, 3 alas de caballería y 9 cohortes de infantes (o mixtas), situadas principalmente en Siene y en $\operatorname{Coptos}^{50}$. Estas tropas auxiliares pueden variar, con tendencia a la baja en el transcurso de los primeros siglos. A final del siglo I los diplomas militares mencionan todavía 3 alas y 7 cohortes, aunque el número quizás se redujo durante el reinado de Trajano. Hasta Diocleciano hubo un número bastante uniforme de tropas auxiliares en Egipto, como se aprecia en la TABLA siguiente, con indicación de los lugares donde se encuentran documentos relativos a tales cohortes y alas, y que permite apreciar sus movimientos y su continuidad.

46 Sí sabemos que aceptó sin poner objeciones las proclamaciones imperiales de Gordiano I, Gordiano II, Pupieno, Balbino y Gordiano III (todas en 238); Filipo (en 244); Decio (en 249); Treboniano Galo (en 251); Emiliano, Valeriano y Galieno (todas en 253). Mediado ya el siglo III combatió a los blemios, una tribu del desierto egipcio, con el gobernador L. Mussius Aemilianus (258-261), y le apoyó en su proclamación imperial en 261 (J. RodríGUEZ GonzÁLEZ, Historia de las legiones romanas, vol. I, pp. 111-112).

47 J. Rodríguez GonzÁlez, Historia de las legiones romanas, vol. I, p. 112.

48 Historia Augusta, Probo, 9, 5. Sobre estos acontecimientos, H.-G. PflaUm, «El imperio romano», en G. Mann / A. Heuss (eds.), Historia Universal, IV, 2: Roma. El mundo romano, 2, Madrid 1985, 477-478.

49 La descripción del triumphus puede leerse en H. A. Aurel. 33-34.

50 S. DARIS, «Le truppe ausiliarie romane in Egitto», ANRW II.10.1 (1988) 743-766. R. ALSTON, 1995, 163-189 (tablas de las unidades auxiliares de Egipto). 
AUXILIA AEGYPTII ${ }^{51}$

\begin{tabular}{|c|c|}
\hline $\begin{array}{l}\text { Nombre de la unidad, y fechas } \\
\text { extremas de su estancia en Egipto }\end{array}$ & $\begin{array}{l}\text { Lugares de Egipto con fechas } \\
\text { certificadas por documentos }{ }^{52}\end{array}$ \\
\hline \multicolumn{2}{|r|}{$A L A E$} \\
\hline Ala Apriana (37/43 - 268/270) & $\begin{array}{l}\text { Heliopolis }(37 / 43)^{53} \text { - Coptos }(83)^{54} \text { - Arsinoite } \\
(120 \text { y } 170)^{55} \text { - Hermopolis Magna }(268 / 270)^{56}\end{array}$ \\
\hline Ala Augusta (57 - 105) & Coptos $(83)^{57}$ - Arsinoite $(103)^{58}$ \\
\hline Ala Commagenorum (48/52 - ca. 165$)$ & Coptos $(83)^{59}$ - Talmis (ca. 165) \\
\hline Ala Veterana Gallica (130 - 244) & $\begin{array}{l}\text { Socnopaiu Nesos }(143)^{61} \text { - Alejandría }(199)^{62} \text { - } \\
\text { Arsinoite }(217)^{63}\end{array}$ \\
\hline Ala Herculiana (185- 215) & Hermopolis (185) $)^{64}$ - Tebas (188 y 202) $)^{65}$ \\
\hline Ala Paulini (27) & Alejandría $(27)^{66}$ \\
\hline Ala I Thracum Mauretana (142 - 288) & $\begin{array}{l}\text { Alejandría }(142)^{67} \text { - Contrapollonospolis } \\
\text { Magna }(156)^{68}-\text { Arsinoite }(173 / 174)^{69}- \\
\text { Alejandría }(199)^{70} \text { - File }(206 / 209)^{71}-\text { Kantara } \\
(288)^{72}\end{array}$ \\
\hline
\end{tabular}

51 Basada en el documentado estudio antes citado de S. DARIS, «Le truppe ausiliarie», 743-766. Se usan las siglas de los repertorios convencionales de papirología y epigrafía. Las siglas RMR corresponden a la obra de R.O. FINK, Roman Military Records on Papyrus, ya citada en nota 1.

52 Insisto en que sólo doy las ubicaciones basadas en documentos bien datados, y que, por tanto, esta tabla debe completarse estos datos con las referencias precisas relativas a otros documentos no fechados, o fechados genéricamente en el siglo, para lo cual remito al trabajo fundamental de S. DARIS, citado en la nota precedente. Se excluyen de esta tabla un ala dudosa (quizás un ala Herculiana) y una cohorte (¿Nerviana?) citada en el diploma CIL XVI 184, fechado en 156-161.

53 P.Mich. III $159=$ ChLA V $280=$ CPL 212.

54 CIL XVI 29.

55 Respectivamente BGU I 69 (año 120) y CIL III 49 (año 170)

56 St. Pal. XX 71.2

57 CIL XVI 29.

58 CIL XVI app. 2; P.Hamb. I, 31.

59 CIL XVI 29.

60 IGRR | 1336

61 P.Grenf. II 51.5

62 CIL III 6581.

63 BGU II 614.

64 BGU III 807.

65 WO 961 /año 188) y 1013 (año 202).

66 SB XVI 12609.

67 CPL 221.

68 BGU II $696=$ RMR 64 I.25.

69 BGU I $26=$ II 447.20 .

70 CIL III 6581.

71 CIL III 75.

72 CIL III 13578. 


\begin{tabular}{|c|c|}
\hline Ala Vocontiorum (37/43 - ca. 165) & $\begin{array}{l}\text { Heliopolis }(37 / 43, y 59)^{73} \text { - Coptos }(55)^{74} \text { - } \\
\text { Porfirite }(113)^{75} \text { - Arsinoite }(122 \text { y } 156)^{76} \text { - } \\
\text { Memnon }(122 / 123)^{77} \text { - Karanis }(156 / 161)^{78} \text { - } \\
\text { Contra Copton }(165)^{79}\end{array}$ \\
\hline Ala Xoitana (37/43) & Heliopolis $(37 / 43)^{80}$ \\
\hline \multicolumn{2}{|r|}{ COHORTES } \\
\hline $\begin{array}{l}\text { Cohors I Ulpia Afrorum Equitata } \\
(117 / 118-177)\end{array}$ & Karanis $(156 / 161)^{81}$ - Arsinoite $(177)^{82}$ \\
\hline $\begin{array}{l}\text { Cohors I Apamenorum Equitata } \\
(144-215)\end{array}$ & $\begin{array}{l}\text { Arsinoite }(144,145,150 / 156,159 / 160)^{83} \text { - } \\
\text { Karanis }(156 / 161)^{84}\end{array}$ \\
\hline $\begin{array}{l}\text { Cohors Camerensiana, Camerensis, } \\
\text { o Cohors Nigri (ca. 18) }\end{array}$ & Apollinis Hydreuma (ca. 18) ${ }^{85}$ \\
\hline $\begin{array}{l}\text { Cohors I Flavia Cilicum Equitata } \\
(81 / 97-218)\end{array}$ & $\begin{array}{l}\text { Hamamat }(81 / 97)^{86} \text { - Coptos }(83)^{87} \text { - Monte } \\
\text { Claudiano }(118)^{88} \text { - Arsinoite }(124)^{89} \text { - Siene } \\
(138 / 142,162 \text { y } 218)^{90} \text { - Contrapollonospolis } \\
\text { Magna }(156)^{91} \text { - Alejandría }(158)^{92} \text { - Oxyrrinco } \\
(158 / 159)^{93} \text { - Filadelfia }(161)^{94} \text { - File }(197 / 218)^{95}\end{array}$ \\
\hline Cohors Facundi (14 d. C.) & Pselcis (14 d. C. $)^{96}$ \\
\hline Cohors Flori (11 d. C.) & Wadi Semna (14 d. C. $)^{97}$ \\
\hline
\end{tabular}

${ }^{73}$ Respectivamente, P.Mich. III 159; y P.Hamb. I 2.

4 P.Wisc. II 53,2.

5 SB I| 4383.4.

${ }^{76}$ Respectivamente: CPL 113; y SB I 5218.

IGRRI 1220.

CIL XVI $184=$ P.Mich. VII 441.

$S B|4280=| G R R \mid 1184$.

so P.Mich. III 159.

1 CIL XVI 184.

2 BGUI 241.4

83 BGU III 729 (año 144); P.Lond. II 178,3 (año 145); BGU II 462 (año 150/156); BGU III 888 (año 159/160).

${ }^{84}$ CIL XVI $184=$ P.Mich. VII 441.

85 SBXVI 12609.

86 IGRRI1243.

87 CIL XVI 29.

88 IGRR I 1255

89 CPRI 18.1-2.

90 CIL III 14147.4 (año 138/142); CIL III 14147.3 (año 138/142); CIL III 6025 (año 140); CIL III 14147.4 (año 162); ILS 8919 = AE 1905, 54 (año 218).

91 BGU II 696 II.22 = RMR 64 .

92 IGRRI 1044.

93 P.Ifao III 11.6

94 P.Phil. 16.1-2.

95 I.Philae II 178.

96 IGRRI 1366.

97 SB VIII 10173 = SEG XX 670. 


\begin{tabular}{|c|c|}
\hline Cohors Ae... Habeti (27 d. C.) & Alejandría (27 d. C.) $)^{98}$ \\
\hline $\begin{array}{l}\text { Cohors I Hispanorum Equitata } \\
(83 \text { - 105) }\end{array}$ & Memnon $(83)^{99}$ - Talmis $(85)^{100}$ - Siene $(99)^{101}$ \\
\hline $\begin{array}{l}\text { Cohors II Ituraeorum Equitata } \\
(39-204)\end{array}$ & $\begin{array}{l}\text { Siene }(39)^{102} \text { - Memnom }(83)^{103} \text { - Siene }(99)^{104} \text { - } \\
\text { Pselcis }(136)^{105} \text { - Talmis }(144 \text { y } 147)^{106}- \\
\text { Karanis }(156 / 161 \text { y } 188)^{107} \text { - Arsinoite }(204)^{108}\end{array}$ \\
\hline Cohors III Ituraeorum (83 - 244) & $\begin{array}{l}\text { Coptos }(83)^{109} \text { - Karanis }(90)^{110}-\text { Wadi Semna } \\
(150 / 153)^{111}-\text { Karanis }(156 / 161)^{112}\end{array}$ \\
\hline Cohors VII Ituraeorum (siglo ॥) & Memnon (s. II) $)^{113}$ \\
\hline Cohors I Augusta Praetoria & Talmis $(98 / 117)^{114}$ - Contrapollonospolis \\
\hline Lusitanorum Equitata (98/117 - 288) & $\begin{array}{l}\text { Magna }(156 \text { y } 180 / 192)^{115}-\text { Karanis } \\
(156 / 161)^{116}-\text { Siene }(159)^{117}- \\
\text { Hieracompolis }(288)^{118}\end{array}$ \\
\hline Cohors II Lusitanorum (109) & Talmis $(109)^{119}$ \\
\hline Cohors I Numidarum (siglo III) ${ }^{120}$ & ¿? \\
\hline $\begin{array}{l}\text { Cohors I Augusta Pannoniorum } \\
\text { (83 - 267) }\end{array}$ & $\begin{array}{l}\text { Coptos }(83)^{121} \text { - Karanis }(156 / 161)^{122}- \\
\text { Oxyrrinco }(267)^{123}\end{array}$ \\
\hline Cohors Sabini (26 - 132/144) & $\begin{array}{l}\text { Alejandría (s. I) }{ }^{124} \text { - Ptolemais Hermiu (s. I I }{ }^{125} \text { - } \\
\text { Arsinoite }(143 / 144)^{126}\end{array}$ \\
\hline
\end{tabular}

98 SBXVI 12609.

99 CIL III 50; CIL XVI 29.

100 IGRR I 1345; SB V 8515.8.

101 CIL III 14147.2 = ILS 8907.

102 CIL III 14147.1 = ILS 8899.

103 CIL XVI 29.

104 CIL III 14147.2 = ILS 8907.

105 SBV 7912.3 = IGRR | 1363.

106 SB I 4601; 4603; 4616 (todos del año 144); y SB V $6521=$ IGRR I 138 (de 147).

107 CIL XVI 184 = P.Mich. VII 441 (de 156/161); y SB IV 7362 (de 188).

108 BGU XI 2024.2.

109 CIL XVI 29.

110 P.Mich. IX 568.

11 AE 1952, 249.

112 CIL XVI $184=$ P.Mich. VII 441.

13 CIL III 59.

114 SBI 4546; SB I 4572.

115 Respectivamente: BGU II 696 = RMR 65, ChLA X 411 (año 156); y SB V $8828=$ IGRR I 1275 (180/192).

116 CIL XVI $184=$ P.Mich. VII 441

117 SB VI 9228.

118 CIL III 22.

119 CIL III 13582.

120 P.Mich. VII $450+455=$ RMR 52 c 6.

121 CIL XVI $20=$ ILS 1996.

122 CIL XVI $184=$ P.Mich. VII 441.

123 P.Oxy. XLI 2951.35.

124 CIL III 6610.

${ }^{125}$ CIL III 12069.

126 BGU III 741. 


\begin{tabular}{|c|c|}
\hline $\begin{array}{l}\text { Cohors I Thebaeorum Equitata } \\
(14 / 37-105)\end{array}$ & Coptos $(14 / 37, \text { y } 83)^{127}$ - Siene $(99)^{128}$ \\
\hline Cohors II Thebaeorum (83 - 177) & $\begin{array}{l}\text { Coptos }(83)^{129} \text { - Tebas }(92)^{130} \text { - Filadelfia (131 y } \\
176 / 177)^{131}-\text { Karanis }(156 / 161)^{132}\end{array}$ \\
\hline Cohors I Thracum (127) & Contrapollonospolis Magna $(127)^{133}$ \\
\hline Cohors II Thracum Equitata (105) & $\begin{array}{l}\text { Siene }(131)^{134} \text { - Tebas }(143)^{135} \text { - Luxor } \\
(195 / 196)^{136}\end{array}$ \\
\hline & NUMERI \\
\hline Numerus Catafractorum (267) $)^{137}$ & Oxyrrinco $(267)^{138}$ \\
\hline Numerus Hemesenorum (s. II-III) ${ }^{139}$ & ¿? \\
\hline Numerus Orientalium (203) ${ }^{140}$ & ¿? \\
\hline $\begin{array}{l}\text { Hadriani Palmyreni Antoniniani } \\
\text { Sagittarii141 }(216-271)\end{array}$ & Coptos $(216)^{142}$ - Oxyrrinco $(271)^{143}$ \\
\hline $\begin{array}{l}\text { Numerus Salaratorum } \\
\text { Peregrinorum (267) }\end{array}$ & Oxyrrinco $(267)^{144}$ \\
\hline \multicolumn{2}{|c|}{ EQUITES SINGULARES } \\
\hline $\begin{array}{l}\text { Equites Singulares Praefecti } \\
(102-258)\end{array}$ & Oxyrrinco $(103)^{145}$ \\
\hline
\end{tabular}

127 CIL III 6628 = ILS 2483 (años 14/37); CIL XVI 29 (año 83).

128 CIL III 14147.2 = ILS 8907.

129 CIL XVI 29.

130 CIL II 37.

131 Respectivamente, BGU VII 1690 = CPL 160 (año 131); y BGU VII 1574.12 (año 1766/177).

132 CIL XVI 184 = P.Mich. VII 441.

133 CPL 159.

134 P.Wisc. I 14.

$135 S B \times 10530$.

136 ASAE 60, 1968, 281-295 n. 23.

137 Cfr. C. ZUCKERMAN, «Le camp de Psôbthis / Sosteos et les cataphractarii», ZPE 100, 1994, 199202.

138 P.Oxy. XLI 295.19.

139 P.Mich VII $454=$ RMR 30,8, ChLA V 276.

140 P.Mich VII $454=$ RMR 30,13, ChLA V 276.

141 J. SchWARTZ, «Les Palmyréniens et I 'Égypte», BSAA 40, 1953, 63-81.

$142 S B \vee 8810=|G R R| 1169$.

143 P.Oxy XLIII 3115.2.

144 P.Oxy XLI 2951.27.

145 P.Oxy VII $1022.26=R M R$ 87. Sobre estos cuerpos especiales, que actúan a modo de guardaespaldas del prefecto de Egipto, ver M.P. SpEIDEL, Guards of the Roman Armies. An Essay on the Singulares of the Provinces, Bonn 1978, con referencias y textos epigráficos a los singulares en Egipto en sus textos n1 69 (del año 102), 72 (de mediados del s.III), 70 (del año 258) y 71 (del s. III). Sobre las funciones cfr. M.P. SPEIDEL, «The Prefect's Horse-Guards and the Supply of Weapons to the Roman Army», en: Proceedinmgs of the XVI Int. Congr. Papyrol. Chico 1981, 405-409. Las funciones a que se refiere Speidel relacionadas con el caballo del prefecto yo las asigno a los stratores: S. PEREA YÉBENES, Los stratores en el ejército romano imperial. Funciones y rangos, Madrid 1998, passim. 
Uno de los objetivos prioritarios de estas tropas auxiliares era proteger Egipto por la frontera Sur, es decir, la llamada «frontera Nubia» ${ }^{146}$. La guarnición principal está en Siene, donde se alojan tres cohortes ${ }^{147}$, de donde partían destacamentos río arriba, pasando las cataratas hasta File, Parembole, Titis, Tafis, Talmis Pselcis y Hiera Sycaminos.

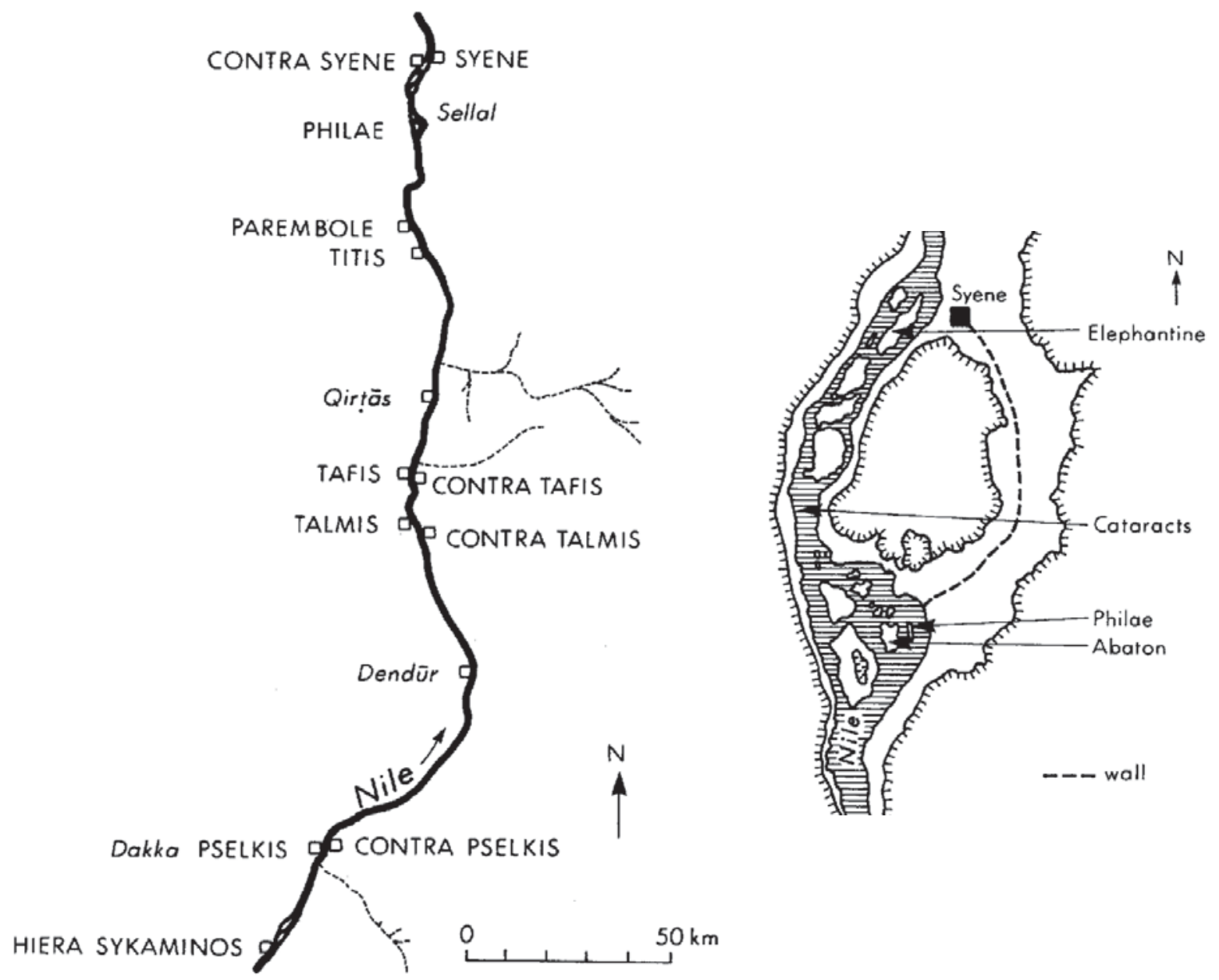

Guarnición romana en Nubia, según M.P. Speidel, 1988, 768 y 774.

En relación con las tropas auxiliares en Egipto hay que recordar por su importancia la magnífica inscripción encontrada en Alejandría, del año 199. Se trata de una dedicación en honor de Septimio Severo y su familia, hecha por los decuriones

146 J. DeSANGes, «Le statut et les limites de la Nubie romaine», Chron. d’ Égypte 44, 1969, 139-147; y sobre todo: M.P. SPEIDEL, «Nubia's Roman Garrison», ANRW, II, 10.1, 1988, 767-798, con toda la documentación.

147 Conocemos estas cohortes y los oficiales que las mandaban por una inscripción del año 99 (CIL III suppl. 2, 14147.2 = ILS 8907 = M.P. SPEIDEL, ANubia's Roman Garrison), 776. Se trata de la I Hispanorum (al mando de Ti.Claudius Africanus); la II Ituraeorum equitata (al mando de Ti. Claudius Berenicianus), y la I Thebaeorum equitata (al mando P. Claudius lustus). 
de las alas Veterana Gallica y I Thracum Mauretana ${ }^{148}$, con motivo de la visita del emperador a la capital de Egipto. De los 25 cognomina conservados en la inscripción 8 son griegos. Para esta época cabe suponer que todos eran ciudadanos romanos. Posiblemente una de estas alas, la Veterana Gallica, hizo una inscripción honorífica para Caracalla, mal conservada ${ }^{149}$, en Alejandría. Estas dos alas son los principales destacamentos de jinetes que sirven de apoyo táctico a la legión II Traiana.

\section{CLASSIS}

En la guarnición de Egipto también cabe recordar la classis Augusta Alexandriana, es decir la flota militar que vigilaba, a modo de policía, las riberas del Nilo. Sabemos que tenía puntos de avituallamiento en Tebas y en Siene, aunque el mando de esta flotilla correspondía a un praefectus classis ecuestre que residía en Alejandría ${ }^{150}$.

Puntualmente podían recalar en el puerto de Alejandría barcos militares de la flota pretoriana de Miseno, como atestigua un documento, que menciona a los «decanoì o decuriones (los que mandan sobre diez classiarii) de la flota ${ }^{151}$. El texto debe datarse entre 162 y 166 . Se ha propuesto que el documento corresponde a una escala alejandrina realizada por Lucio Vero en su expedición que partió de Bríndisi en 162 y se dirigía a Antioquía para afrontar la guerra contra los partos. La expedición acabó en 166. El carácter fragmentario del texto no permite afinar más a qué momento corresponde esta dedicación imperial de los suboficiales de la flota que hacen una escala en Alejandría con el tiempo suficiente para erigir un inscripción honorífica a los co-emperadores.

\section{BAJO IMPERIO}

Para este periodo las fuentes para el estudio del ejército romano en Egipto son, en primer lugar, las arqueológicas. Tienen una importancia capital las excavaciones

148 CIL III 6581; F. KAYSER, n1 106. [IMP(eratori) CAES(ari)] / DIVI M. [ANTONINI PII GERMANICI SARMATICI]/ FILIO DIVI COMMODI FRATRI DIVI ANTON[INI] / PII NEPOTI DIVI HADRIANI PRONEPOTI DIVI / TRAIANI PARTHIC(i) ABNEP[OTI] DIVI NERVAE / ABNEPOTI L.SEPTIMIO SEVERO P[IO] / PERTINAC(i) AVG(usto) ADIABENI[CO PARTH(ico) MAX(imo) PONT(ifici) / MAX(imo) TRIBVNICI(ae) POTESTATIS VII IM[P(eratori) XI] / CO(n)S(uli) II P(atri) P(atriae) PROCONSVL(i) / DECVRIONES ALARES / VETERANAE GALLIC(ae) ET THRAC(um) MAVR(etanae). Siguen los nombres de los decuriones, en dos columnas de 16, algunos de ellos perdidos. Se trata de alas quingenarias, es decir, de 500 hombres, divididas cada una de ellas en 16 turmas de 30 hombres cada una.

149 F. KAYSER, n. ${ }^{\circ} 106$ bis.

150 M. Zyromsky, Praefectus Classis: the Commanders of Roman Imperial Navy during the Principate, Poznan 2001. Estudio prosopográfico.

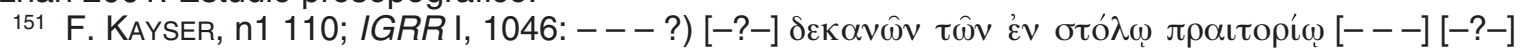

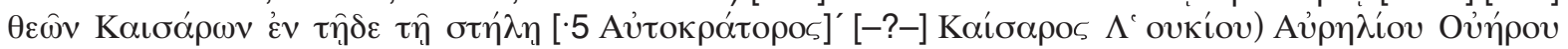

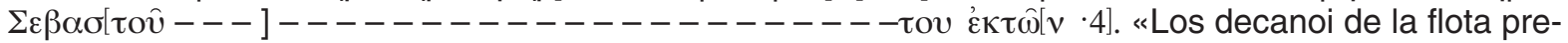
toriana... de los divinos Césares... sobre esta estela... [ ... del emperador César Lucio Vero Augusto...». 
que han sacado a la luz los campamentos que se multiplican a partir de la reforma militar de Diocleciano, concluida por Constantino, que supuso la reorganización de todas las legiones ${ }^{152}$. El reinado de Diocleciano marca la inflexión entre Alto y Bajo Imperio en el concepto de defensa y estrategia del Imperio. En esencia la reforma consistió en formar legiones de unos 3000 hombres (en lugar de los 5500 con que contaban aproximadamente las legiones altoimperiales), resultando por tanto un número mayor de legiones, en proporción al mayor número de nuevas provincias resultantes tras las subdivisiones territoriales llevada a cabo por el propio Diocleciano. Desde el punto de vista estratégico la reforma permitía en situar las legiones en las fronteras, empeñadas en la continua defensa del limes, al tiempo que unidades de nueva creación constituidas por tropas de élite eran las encargadas de la defensa del palacio ${ }^{153}$, de la persona del emperador, y de ejército su ejército «en movimiento". Estos acompañantes de séquito son los comitatenses, y este grueso de ejército es conocido con el nombre genérico de comitatus. Las reformas militares y administrativas, naturalmente, afectaron también a Egipto.

Diocleciano había hecho retroceder la frontera meridional de Egipto hasta la primera catarata, poniendo distancia con el territorio de los blemios que hostigaban la frontera ${ }^{154}$.

Diocleciano dividió Egipto en tres provincias, con nuevas guarniciones:

a) (Aegyptus) Thebaida: legión I Maximiana ${ }^{155}$ + legión II Flavia Constantia, ambas con guarnición en Luxor ${ }^{156}$;

b) (Aegyptus) lovia: legión II Traiana + la nueva III Diocletiana ${ }^{157}$,

152 H.M.D. PARKER, «The Legions of Diocletian and Constantine», JRS, 23, 1933, 175-189. J. RodRíGUEZ GonzÁLEZ, Historia de las legiones romanas, vol. II, 451-452. J.C. GolvIN / M. REDDÉ, “Quelques recherches récentes sur l' archéologie militaire romain en Égypte», CRAl 1986, 172-196. G. WAGNER, «Le camp romain de Doush (Oasis de Khargeh - Égypte)», Studien zu den Militärgrenzen Roms III. 13 Internationaler Limeskongress Aalen 1983. Vorträge, Forchungen und Berichte zur Vor- und Frühgeschichte in Baden-Würtemberg 20. Stuttgart 1986. K.A. WORP, «Observations on some Military Camps and Place Names in Lower Egypt», ZPE 87, 1991, 291-295. Sobre los aspectos económicos y paga de los soldados en época de Diocleciano, ver R.P. DunCAN-JONES, «Pay and Numbers in Diocletian`s Army», Chiron 8, 1978, 541-560.

153 Especial relevancia tienen, ya en época de Constantino I, las llamadas Scholae Palatinae, que son las herederas naturales de las antiguas Cohortes Pretorianas (disueltas en 312), ahora con funciones civiles y militares. Sobre estas tropas, R.I. FRANK, Scholae Palatinae. The Palace Guards of the Late Roman Empire, Roma 1969.

154 L. CASTIGLIONE, «Diocletianus und die Blemmyes», Zeitschr. Für Ägystische Sprache 96, 1970, 90103; R.T. UPDEGRAFF, «The Blemmyes I: The Rise of the Blemmyes and the Roman Withdrawal from Nubia under Diocletian (with Additional Remarks by L. Törok, Budapest)», ANRW II, 10, 1, 1988, 44-106; St. WiLliams, Diocleziano. Un autocrate riformatore, Genova 1995, 131-132 y 144. Sobre el Egipto bajoimperial: R.S. BAGnALL, Egypt in Late Anriquity, Princeton University Press 1993.

155 D. van Berchem, L'armée de Dioclétien et la réforme constantinienne, París, 1952, 62.

156 Antes del año 295 como atestigua el P.Oxy 43. El campamento fue ocupado por la cohors // Thracum Equitata en 195196; y por las legiones I Maximiana y II Flavia Constantia en tiempos de Diocleciano. M. SPEIDEL, «Legion II Flavia Constantia at Luxor», Roman Army Studies II, Stuttgart 1992, 396399. La arqueología del campamento: M. El-SAGIR / J.C. Golvin / M. REDdÉ / E.S. HeGAZY / G WAGNER, Le camp romain de Louqsor, MIFAO 83, El Cairo 1986.

157 D. van Berchem, L'armée de Dioclétien, 61. 
c) (Aegyptus) Herculea: destacamentos de dos legiones danubianas, la $V$ Macedonica + la XIII Gemina ${ }^{158}$.

En efecto, éste era un ejército nuevo ${ }^{159}$, pues se dividieron antiguas guarniciones legionarias, se crearon nuevos destacamentos, y nuevas unidades auxiliares; y se transformó el concepto de estrategia, abandonando el papel del ejército como fuerza estática disuasoria, para ejercer un papel nuevo, de tipo policial y fiscal, si damos crédito a la antigua hipótesis de D. van Berchem ${ }^{160}$, aunque quizás ese papel policial y recaudador haya que retrasarlo unos años, a partir del $293^{161}$. Ese año es crucial. Se instaura la tetrarquía. Diocleciano, que gobierna en Oriente, nombra César a Galerio. Éste muy pronto (en diciembre de 293) recibe el encargo de marchar a Egipto para sofocar unas revueltas surgidas en Busiris y Coptos, importantes encrucijadas caravaneras del Alto Egipto. Las victorias le permite incorporar a su titulatura honorífica los sobrenombres de Aegyptiacus maximus y de Thebaicus maximus, aunque no lo hará hasta el 305 en que alcanza la dignidad de Augusto, aunque antes (en 298-299) había hecho acuñar en Alejandría una serie de monedas en cuyos reversos se pone la leyenda CONCORDIA MILITVM ${ }^{162}$.

La imagen muestra a Galerio en traje militar recibiendo del mismo Júpiter una Victoria posada sobre un globo terráqueo, metáfora explícita de las aspiraciones del César a un poder universal con el placet divino.
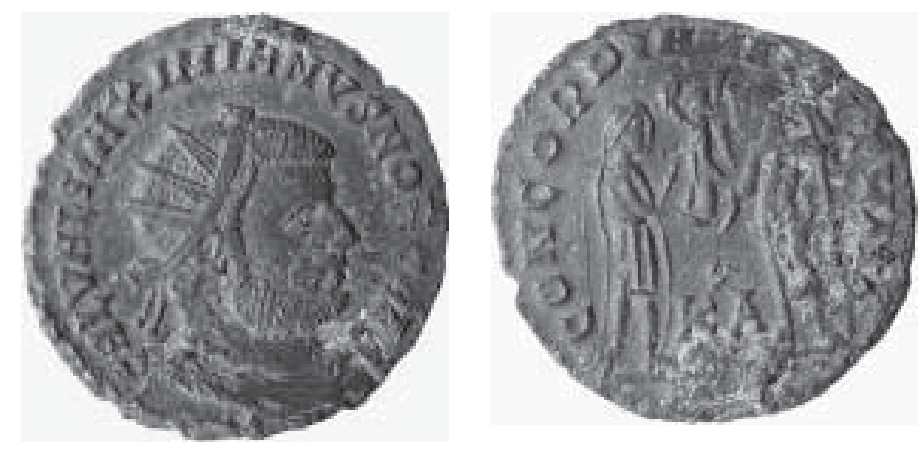

Desde el punto de vista arqueológico el Egipto «de Diocleciano» es absolutamente excepcional, pues a partir de $287 / 288$ se inicia un vasto programa de construcción de campamentos en Egipto, dentro de otro programa aún más amplio cuya finalidad era proteger las fronteras del Imperio. Parece que existe consenso en

158 D. van Berchem, L’armée de Dioclétien, 60, 105, 106.

159 Es significativo que el magnífico estudio de J. LESQUIER de 1918 acabara precisamente con las reformas dioclecianeas.

160 D. van Berchem, L'armée de Dioclétien, 70.

161 O quizás a agosto de 296, en que cesan las acuñaciones imperiales alejandrinas con leyenda griega, o a marzo del 297 en que se publica el edicto de tasas de Aristio Optato $(P$. Cairo Isid. 1= edición de A.E.R. Boak / H.C. Youtie, The Archive of Aurelius Isidorus in the Egyptian Museum, Cairo, and the University of Michigan, Ann Arbor 1960). Son medidas fiscales y económicas que justificarían un cambio sustancial en las funciones militares de algunas unidades de Egipto.

162 Roman Imperial Coinage VI, Alexandria 48b. En el anverso: GAL·VAL·MAXIMIANVS.NOB. CAES. 
considerar el campamento de Dyonisias el modelo a imitar ${ }^{163}$. Los más parecidos son los fuertes de Tell el-Herr, en el Delta oriental, y el de Mehendi en Nubia ${ }^{164}$. El programa recalifica ciudades ya bien guarnecidas, como Coptos, que es rebautizada hacia 295 con el nombre de Potecoptos ${ }^{165}$ y convertida en un fuerte militar.

Mientras Diocleciano guerreaba en Persia ${ }^{166}$, se extendió por Egipto una revuelta generalizada que fue aprovechada por Lucio Domicio Domiciano, y su corrector Aurelio Aquileo, para asaltar el trono. Este intento de usurpación ha sido fijado por unos en 296-297 167 y por otros en 297-298 ${ }^{168}$. La rebelión fue atajada por el propio Diocleciano, aunque no fue fácil. El historiador Eutropio habla de 8 meses de asedio a la ciudad de Alejandría. Con la ciudad no cayeron sólo los asediados sino que el orden institucional volvió a todo el país del Nilo ${ }^{169}$.

La reforma territorial administrativa de Diocleciano en Egipto ${ }^{170}$ no influyó a corto plazo en las funciones que hasta entonces había tenido la legión II Traiana, salvo en el hecho de que sus efectivos quedaron muy mermados en el país del Nilo ${ }^{171}$. Contingentes de la legión se documentan a comienzos del siglo IV en Hermunthus, Apollinopolis Superioris, Ptolemais y Tentyra ${ }^{172}$, en la recién creada provincia egipcia de Tebaida Prima. Su misión es de tipo policial: vigilancia de las fronteras y de las rutas comerciales que conectan el Nilo y los puertos del Mar Rojo ${ }^{173}$.

163 J.M. CARRIÉ, «Les Castra Dionysiados et l' évolution de l' architecture militaire romaine tardive», MEFRA 86, 1974, 819-850; R. ALston, Soldier and Society in Roman Egypt, a Social History. Londres New York 1995, 156. Interesa de este libro especialmente el apéndice 2: «The archaeology of the Army».

164 R.S. BagnalL, «Army and Policy in Roman Upper Egypt», Journal of the American research Center in Egypt 14, 1977, 67-86; A.K. Bowman, «The Military Occupation of Upper Egypt in the Reign of Diocletian», BASP 15, 1978, 25-38.

165 P. Oxy 2673.9.

166 T.D. Barnes, «Imperial Campaigns, A.D. 285-311», Phoenix 30, 1976, 174-193.

167 J. Rodríguez González, Historia de las legiones, II, 562, en su resumen de historia militar de la provincia de Egipto. Cfr. C. ZUCKERMAN, «Les campagnes des trétrarques, 296-298. Notes de chronologie», Ant. Trard. 2, 1994, 65-70.

168 Cabe destacar la monografía de J. SchwarTZ, L. Domitius Domitianus (Étude numismatique et papyrologique), Pap. Brux. 12, Bruselas 1975 (propone la fecha 297-298). Un outline sobre los acontecimientos y su contextualización egipcia, J.-Y. CARREZ-MARATRAY, en D. VALVELle / J.Y. CARREZMARATRAY, Le camp romain du BasEmpire à Tell ElHerr, Paris 2000, 31-32. Cfr. R. RÉMONDON, «Problèmes militaires en Égypte et dans l' Empire à la fin du IV siècle», Revue historique 213, 1955, 2138.

169 Eutr. Brev. IX, 23: Diocletianus obsessum Alexandriae Achilleum octavo fere mense superavit eumque interfecit. Victoria acerbe usus est; totam Aegyptum gravibus proscriptionibus caedibusque foedavit. Ea tamen occasione ordinavit provide multa et disposuit, quae ad nostram aetatem manent.

170 Para la cuestión de la remodelación de la «gran estrategia» dicolecianea, con especial referencia a Egipto: E. LuTTWAK, The Grand Strategy of the Roman Empire, from the First Century A.D. to the Third, The John Hopkins University Press 1976, 175-178.

171 Durante la rebelión de Domicio Domiciano un destacamento de esta legión apoyó las operaciones de Maximiano en las Mauretanias, Numidia y África proconsular. En Mauretania Tingintana quedó acuartelada una parte de esta legión.

172 J. Rodríguez GonzÁlez, Historia de las legiones romanas, vol. I, p. 112.

173 J.M. CARRIÉ, «Le rôle économique de l' armée dans L'Égypte romaine», en Armées et fiscalité dans le monde antique, Paris 1977, 373-393. J. DESANGES, «Les relations de l' Empire romain avec I 'Afrique nilotique et érytréenne, d' Auguste à Probus», ANRW II, 10, 1, 1988, 3-43. J.J. AuBERT, «Policing the Countryside: Soldiers and Civilians in Egyptian Villages in the Third and Fourth Centuries A.D.», en: Y. Le Bohec (ed.), La Hiérarchie (Rangordnung) de l' Armée Romanine sous le Haut Empire, Paria 1995, 258. 
Campamentos y unidades en la región del Delta Oriental, de 289 a 395 (según J.-Y. Carrez-Maratray)

\begin{tabular}{|c|c|c|c|}
\hline Ubicación & Fuerte romano excavado & Unidad documentada & Fecha \\
\hline Rhinocura & $\begin{array}{l}\text { (Sólo quedan restos } \\
\text { islámicos) }\end{array}$ & ala veterana Gallorum & $?-395 ?$ \\
\hline $\begin{array}{l}\text { Scenae extra } \\
\text { Geros }\end{array}$ & sin datos & $\begin{array}{l}\text { desconocida; } \\
\text { a partir de } 324 \\
\text { destacamentos } \\
\text { legionarios o soldados } \\
\text { I del ala I Herculia }\end{array}$ & $324-395 ?$ \\
\hline Pelusium & Tell el Farama 7,2 Ha & equites Stablesiani & $?-395 ?$ \\
\hline Magdoulum & Tell el-Herr 0,8 Ha & desconocida & $\begin{array}{l}289-? \\
360-?\end{array}$ \\
\hline Silé & Tell Abou Seifa 1,6 Ha & $\begin{array}{l}\text { ala I Thracum Mauretana } \\
\text { ala I Aegyptiorum }\end{array}$ & $\begin{array}{l}288-? \\
?-395 ?\end{array}$ \\
\hline Clysma & Kom Qulzûm & desconocida & romana \\
\hline
\end{tabular}

La tabla precedente refleja la distribución de las tropas y los fuertes de la provincia Augustamnica en los siglos III y IV ${ }^{174}$. Destacan por su importancia varias guarniciones situadas al norte, en la ruta hacia las provincias orientales por la ruta terrestre del norte del Sinaí175, conectando con la región militar fortificada «dioclecianea» de la región del Jordán ${ }^{176}$. Los citados castra egipcios son:

174 J.-Y. Carrez-Maratray, «L' occupation militaire de la région», en D. Valvelle / J.Y. CarrezMARATRAY, Le camp romain du BasEmpire, 53-55.

175 D. MeREDITH, «The Roman Remains in the Eastern Desert of Egypt» JEA 38, 1952, 94-11 y 39 , 1953, 95-106 [debe completarse y/o corregirse con el estudio posterior de M. REDDÉ, / J.-C. GoLVIN, «Du Nil à la Mer Rouge: documents anciens et nouveaux sur les routes du désert oriental d' Égypte», Karthago 21, 1987, 5-64]. P. FIGUERAS, «The North Sinai Road in the Graeco-Roman Period», SCl 8-9, 19851988, 53-65. D.F. GRAF, «Les circulations entre Syrie, Palestine, Jordanie et Sinaï aux époques grecque et romaine", en: D. VAlbelle, C. Bonnet (eds.), Le Sinaï durant l' Antiquité et le Moyen Age. 4000 ans d' Histoire pour un désert, Paris 1998, 107-113.

176 J. EADIE, «The Transformation of the Eastern Frontier, 260305», en R. MATHISEN / H. SIVAN (eds), Shifting Frontiers in Late Antiquity, Variorum, London 1996, 7282. M. ED-DIN MUSTAFA / H. JARITZ, «A Roman Fortess at Nag' el Hagar, First Preliminary Report», ASAE 70, 1985, 31-31. R. FelLmAnN, «Le Camp de Dioclétien à Palmyre et l' architecture militaire du Bas Empire», Mélanges d' histoire ancienne et d' archéologie offerts à Paul Collart. Cahiers d' archéologie romaine 5. Lausanne. Z.T. FIEMA, «Military Architecture and teh Defence 'System' of Roman Byzantine Southern Jordan. A Critical Appraisal of Current Interpretations» SHA Jordan 5, 1995, 261-269. A. GABRIEL, «Kasr el-Heir», Syria 8, 1927, 302-329. V.A. CLARK, «The Roman Castellum of Qasr Bshir», en: T.S. PARKER (ed.), The Roman Frontier in Central Jordan. Interim Report on the Limes Arabicus Project 1980-1985, BAR-IS 340, II, Oxford 1987, 457-495. J. ScHWARTZ, «Une forteresse construite sous Dioclétien: Qar-Qârun», CRAl 1951, 90-97. D. WHITCOMB, «Diocletian's Misr at Aqaba», ZDPV 106, 1990, 156-161. D.F. GRAF, "Saracens and the Defence of the Arabian Frontier», BASOR 229, 1978, 1-26. D.F. GRAF, «Rome and the Saracens: Reassessing the nomadic Menace", en: T. Fahd (ed.), L'Arabie préislamique et son enviroment historique et culturel. Actes du Colloque de Strasbourg 24-27 juin 1987, Leiden 1989, 341-400. S. GREGORY, Roman Military Architectura on the Eastern Frontier, Amsterdam 1995. T. S. PARKER, The Roman Frontier in Central Jordan. Interim Report on the Limes Arabicus Project, 1980-1985. BAR-IS 340. M. REDDÉ, «Dioclétien et les fortifications militaires de I' antiquité tardive, quelques considérations de méthode», Antiquité Tardive 3, 1995, 91-124. 
-Tell el-Herr / Magdolum. De 90 metros de ladro. Construido en época de Diocleciano, en 286-296. Es un campamento de tropas auxiliares que acogió posiblemente al ala I Thracum Mauretana, documentada en Silé.

-Pelusium ${ }^{177}$. Parece que este campamento acogió a un famoso regimiento de élite, los Equites Stablesiani, que M Speidel sitúa ya a finales del siglo III $^{178}$. En todo caso su presencia está certificada hacia 395 por la Notitia Dignitatum.

-Scenae extra Geros ${ }^{179}$. Es el campamento del ala I Herculia, documentada a finales del siglo III y comienzos del IV ${ }^{180}$.

- Silé / Tell Abou Seifa. Parece que la guarnición auxiliar de Silé se posicionó a favor de la causa de Domitius Domitianus en $297^{181}$, aunque ni éste ni otros campamentos de la zona muestran niveles de destrucción importantes (datables) en esas fechas. De Silé procede un documento militar, la inscripción, datada en 288, que certifica la unidad que lo ocupó a finales del siglo III y cabe pensar que en el IV, el ala I Thracum Mauretana. El texto ${ }^{182}$ alude, para honrarlos, a la solidaridad divina de Diocleciano «Jupiterino» (lovius) y Maximiano «Hercúleo» y a la Victoria, a su providentia y su maiestas.

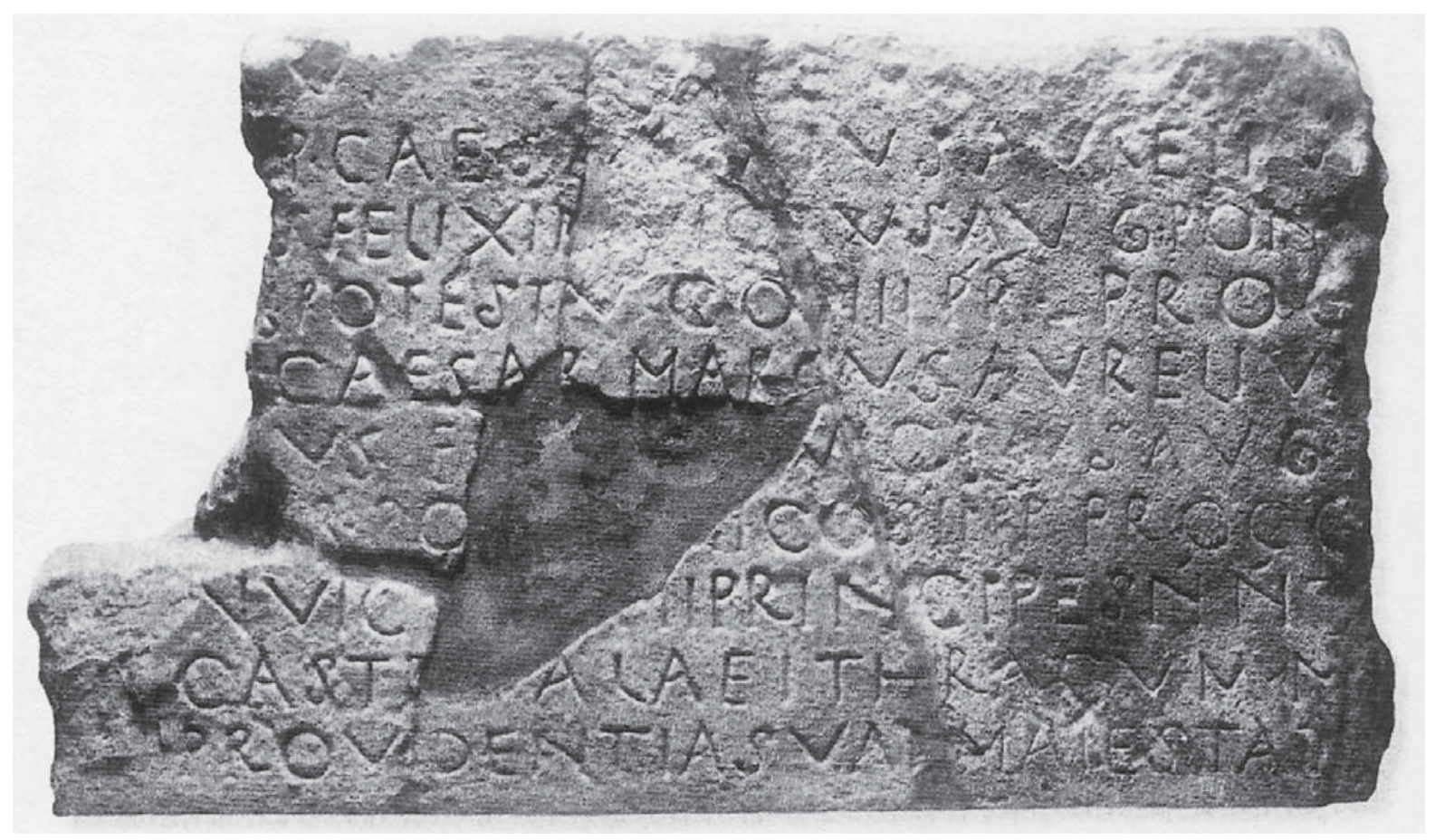

177 M. Abd el-Mansoud / A. El-TabA'l / P. Grossmann, «The Late Roman Army Castrum at Pelusium (Tall al-Farama)», CRIPEL 16, 95-103.

178 M. SPEIDEL, «Stablesiani. The Raising of New Cavalry Units during the Crisis of the Roman Empire», Chiron 4, 1974, 541-546 (= Roman Army Studies, I, Amsterdam 1984, 391-396).

179 Es decir, «hacia Gerasa», como indica la Notitia Dignitatum.

180 Se hace mención a esta unidad en Scenae en P.Oxy L 3574 y 3580.

181 Para la discusión, J.-Y. CARREZ-MARATRAY, «L' occupation militaire de la région», en D. VALVELLE / J.Y. Carrez-Maratray, Le camp romain du BasEmpire, 54.

${ }_{182}$ CIL III supl.2, 13578. La foto procede de: J.-Y. CarReZ-MaratraY, loc.cit., 28. 
El citado campamento acogió a finales del siglo Iv al ala I Aegyptiorum, como indica la Notitia Dignitatum.

Tras la muerte de Teodosio I, el limes Aegypti tiene una nueva remodelación. Hacia el año 400 Egipto como provincia de frontera está formado por tres provincias de menor tamaño que las dioclecianeas, pues se renuncia a las regiones históricas del Alto Egipto ${ }^{183}$, así como las adyacentes Lybias Duas, situadas al occidente del Delta. El nuevo territorio administrativo y militar de Egipto queda así:

a) Egipto propiamente llamado (Aegyptus): el delta occidental

b) La Augustamnica: el delta oriental.

c) La Arcadia: el «Egipto Medio»

La remodelación territorial exige la adecuación de la legión II Traiana, que se divide en dos contingentes, en la provincia de Aegyptus: uno a las órdenes del comes limitis Aegypti, acuartelado en Parembole ${ }^{184}$, y el otro, a disposición del Dux Thebaidos, tenía su base en Apollinopolis Superioris, en la provincia de Tebaida Prima, superponiéndose al sector guarnecido por la legión tardoimperial III Diocletiana $^{185}$.

Un documento excepcional para conocer el reparto de tropas en esta época es la Notitia Dignitatum, que refleja, como para otras partes del Imperio, una foto-finish del poder militar romano en la provincia, aportando el nombre las tropas y la ubicación de sus fuertes ${ }^{186}$, y en consecuencia informando de los puntos estratégicos. He aquí la guarnición de Egipto según el citado documento ${ }^{187}$.

\section{XXVIII}

\section{COMES LIMITIS AEGYPTI}

13 SUB DISPOSITIONE VIRI SPECTABILIS COMITIS REI MILITARIS PER AEGYPTUM:

14 Legio quinta Macedonica, Memfi.

15 Legio tertiadecima Gemina, Babilona.

16 Equites Stablesiani, Pelusio.

183 Pues la antigua provincia de Tebaida traslada ahora su límite al sur de Oxyrrinco, que es de hecho la frontera más meridional de Egipto desde los inicios del siglo v.

184 Not Dign. Or. XXVII 19.

185 Not Dign. XXXI 34.

186 A veces resulta difícil poner en un punto concreto del territorio (del mapa) las guarniciones mencionadas en la Notitia Dignitatum. La lista de guarniciones de Egipto está tomada de J.-Y. CARREZ-MARATRAY, «L' occupation militaire de la région», en D. VALVELLE / J.Y. CARREZ-MARATRAY, Le camp romain du BasEmpire, 49.

187 Not. Dig. Or. XXVIII, XXXI. Reproducido y agrupado por categoría de unidades militares, en R. Alston, 1995, 190-191. 
17 Equites Saraceni Thamudeni, Scenas Veteranorum.

18 Legio tertia Diocletiana / Thebaidos, Andro.

19 Legio secunda Traiana, Parembole.

20 Ala Theodosiana nuper constituta.

21 Ala Arcadiana nuper constituta.

22 Ala secunda Armeniorum, Oasi minore.

23 ET QUAE DE MINORE LATERCULO EMITTUNTUR:

24 Ala tertia Arabum, Therenuthi.

25 Ala octava Vandilorum, Nee.

26 Ala septima Sarmatorum, Scenas Mandrorum.

27 Ala prima Aegyptiorum, Selle.

28 Ala veterana Gallorum, Rinocorura.

29 Ala prima Herculia, Scenas extra Gerasa.

30 Ala quinta Raetorum,Scenas Veteranorum.

31 Ala prima Tingitana, Thinunepsi.

32 Ala Apriana Hipponos.

33 Ala secunda Assyriorum, Sosteos.

34 Ala quinta Praelectorum, Dionisiada.

35 Cohors tertia Galatarum, Cefro.

36 Cohors secunda Astarum, Busiris.

37 Provinciae Augustamilicae:

38 Ala secunda Ulpia Afrorum, Thaubasteos.

39 Ala secunda Aegyptiorum, Tacasiria.

40 Cohors prima sagittariorum, Naithu.

41 Cohors prima Augusta Pannoniorum, Tohu.

42 Cohors prima Epireorum, Castra Iudaeorum.

43 Cohors quarta luthungorum, Afrodito.

44 Cohors secunda Ituraeorum, Aiy.

45 Cohors secunda Thracum, Muson.

46 Cohors quarta Numidarum, Narmunthi. 


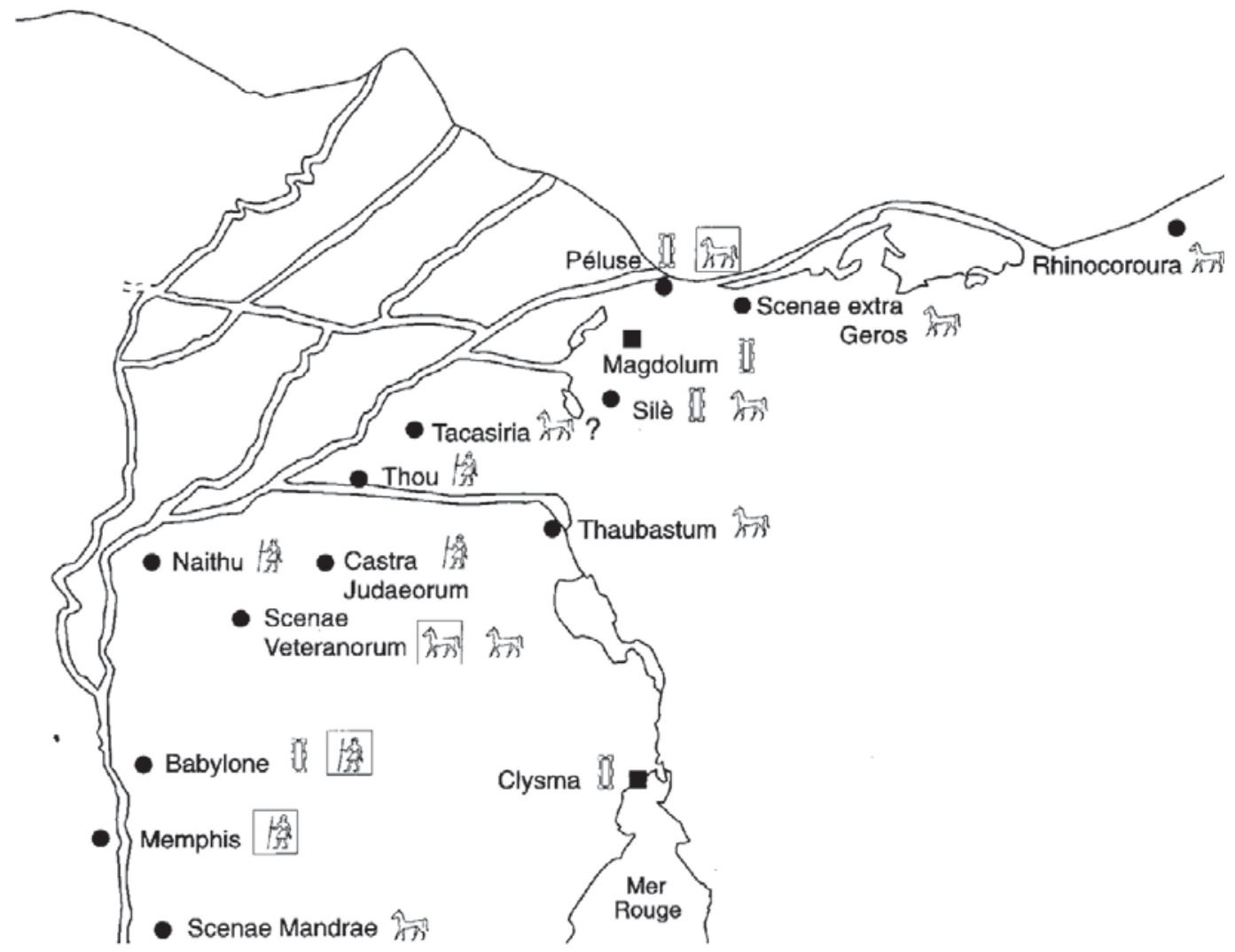

Guarnición del Delta oriental, hacia el año 400, según la Noticia Dignitatum.

La simple observación de este mapa, y de la lista de la Notitia, indica el notable aumento de unidades en Egipto, y en especial las situadas al este, como si se temieran invasiones o ataques desde oriente. Este reforzamiento también tenía como finalidad asegurar - como lo había procurado siempre- las rutas comerciales que recorren el país de norte a sur, y hacia el mar. El interés principal es mantener en su integridad territorial, cada vez menor, a Egipto según las fronteras establecidas en tiempos de Teodosio. Desde el sur (el alto curso del Nilo) las incursiones de los pueblos periféricos, como el de los blemios, era secular, y un problema no resuelto en la época tardía.

El ejército romano, desde el siglo I al vı se muestra siempre en su doble función de mantener la seguridad interna a nivel policial, complementado con la vigilancia de las rutas, y, por otro lado, la prevención de ataques exteriores desde el corazón de África, y, desde el Oriente por la frontera sinaítica. Controlar las vías de acceso al país - un país tan determinado y blindado por su geografía- era controlar las invasiones. El despliegue de fuertes a lo largo del curso del Nilo, pero principalmente en su curso alto, en la zona de las Cataratas, muestra esa preocupación por vigilar «las válvulas» del país. Lo mismo puede decirse del lado oriental del Delta, que en el Bajo Imperio se refuerza extraordinariamente, dentro de un plan general estratégico diseñado especialmente para Oriente por Diocleciano. La arqueología 
ha puesto de relieve la excepcionalidad de la red de campamentos que se despliegan en el desierto, a lo largo de los caminos y rutas que llevan a Siria y a Persia. Las vías de expansión comercial de Egipto van a ser también las vías de penetración de los invasores árabes en el siglo vII. Naturalmente no sabemos el nivel de preparación y resistencia que tenía el ejército bajoimperial en Egipto, pero no hay motivos para pensar que fuera menor que el nivel que mantuvo en los tres primeros siglos. La multiplicación del número de unidades no significa que creciera espectacularmente el número de soldados. Egipto, como todas las regiones, provincias o prefecturas, mantuvieron en los últimos siglos del imperio un nivel grande de tropas, de cuya eficacia no cabe dudar aunque ciertamente no hay que compararlos con las tropas del Alto Imperio. El ejército romano de Egipto bajoimperial no es muy distinto al de otras provincias, y como en otros lugares se caracteriza por varias circunstancias: su dispersión estratégica y su reclutamiento.

La dispersión estratégica viene dada por la propia característica de las unidades, más pequeñas, más móviles, que ocupan uno u otro fuerte en razón de las necesidades, al tiempo que crecen el número de campamentos, de no grande extensión pero muy fortificados ${ }^{188}$, pensados principalmente para acoger a tropas de caballería. Un ejemplo es campamento de Tell el-Herr (Magdolum) en el sector oriental del Delta, muy bien estudiado recientemente ${ }^{189}$. En el entorno del mismo se han encontrado unas pequeñas estelas de jinetes, singulares en su ejecución y en su representación, que muestran un equipamiento único ${ }^{190}$, y evidencian cómo, en el Imperio romano tardío, las tradiciones egipcias milenarias están presentes de algún modo en la religiosidad del soldado romano, del jinete que recorre en su montura los caminos desérticos bajo la protección omnipresente del dios-Halcón, Horus en su acepción solar como hijo de Ra.

El otro factor, el reclutamiento, se caracteriza por un mayor número de soldados locales, campesinos que cambian la azada por la espada, sin perder de vista a su familia y sus haciendas; $y$, por otro lado, un reclutamiento cada vez mayor de «tropas bárbaras» entendiendo por tal, en el caso de Egipto, de hombres procedentes de las tribus periféricas. En realidad el mecanismo no había cambiado mucho respecto a los siglos I-III, aunque la inestabilidad política y económica, como en todo el orbe romano, actuó aquí también como aceleradores de la crisis. Cabe apuntar finalmente un posible factor de debilidad interna: el fuerte influjo e implantación del cristianismo en Egipto. Esta circunstancia, si no de forma definitiva, pudo contribuir también a la «debilitación» del aparato militar, que en Egipto, como en otras provincias, vio minado por múltiples circunstancias el edificio de su integridad política y territorial.

188 Ver planos de los campamentos al final del presente estudio.

189 D. VALVELLe / J.-Y. CARREZ-MatraRAY Le camp romain du Bas Empire... 2000, citado a lo largo de este trabajo.

190 D. Valvelle / J.-Y. Carrez-Matraray Le camp romain du Bas Empire, 2000, 62-63. 


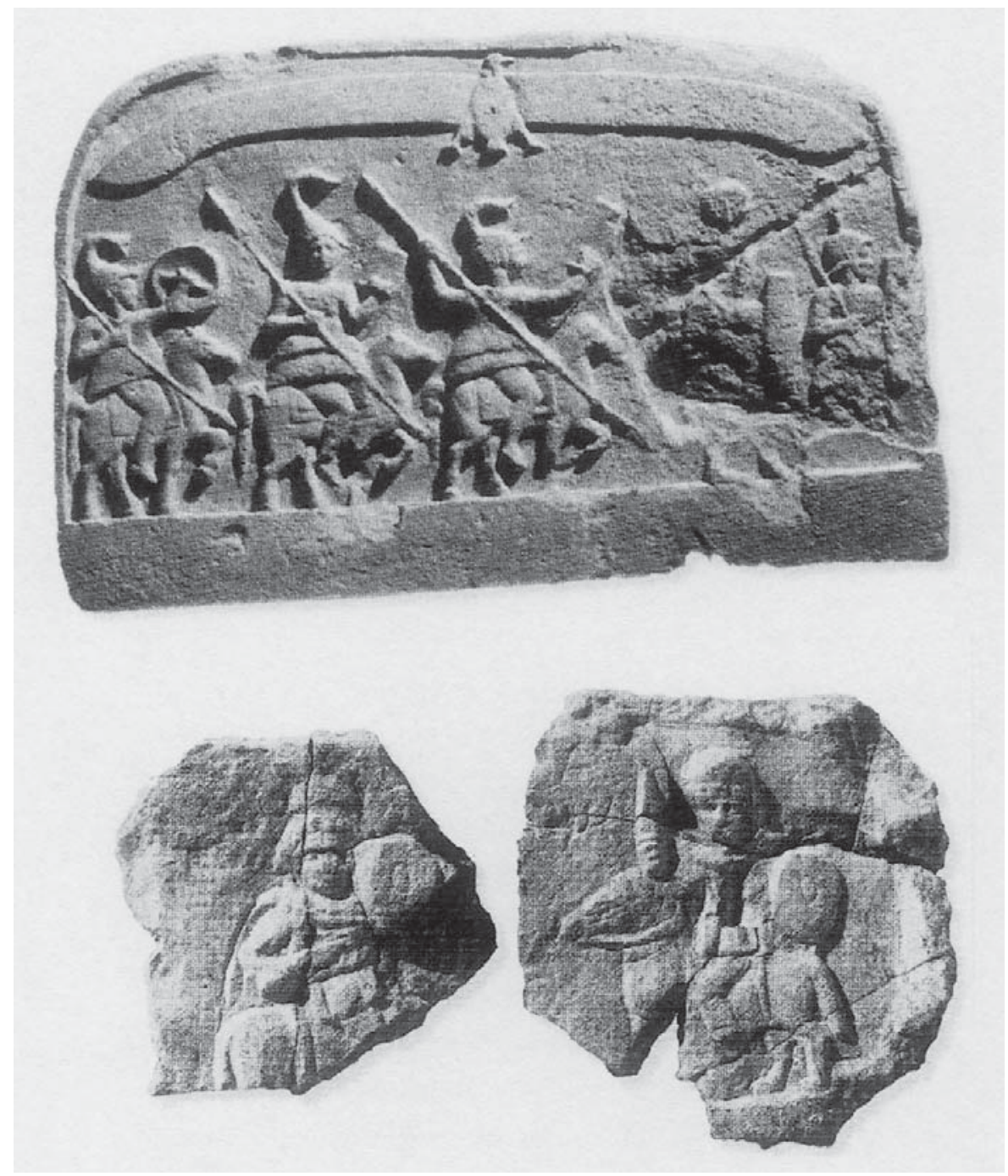

Jinetes romanos. Relieves de piedra, Tell el-Herr. 


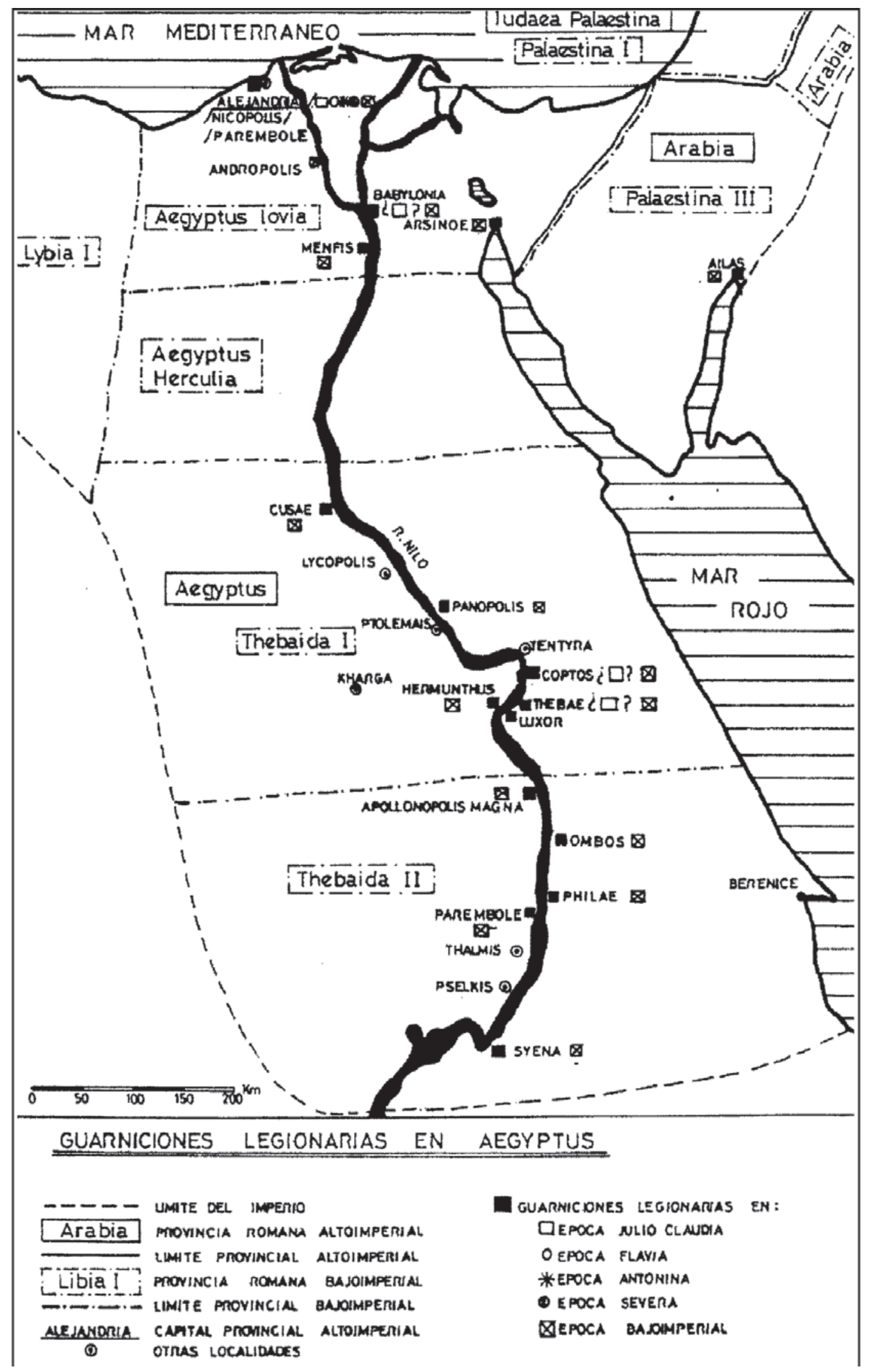

Guarnición de Egipto (Según J. Rodríguez González, 2001) 
PLANOS DE VARIOS CAMPAMENTOS ROMANOS BAJOIMPERIALES DEL DELTA ORIENTAL DE EGIPTO Y DEL LIMES ARABICUS
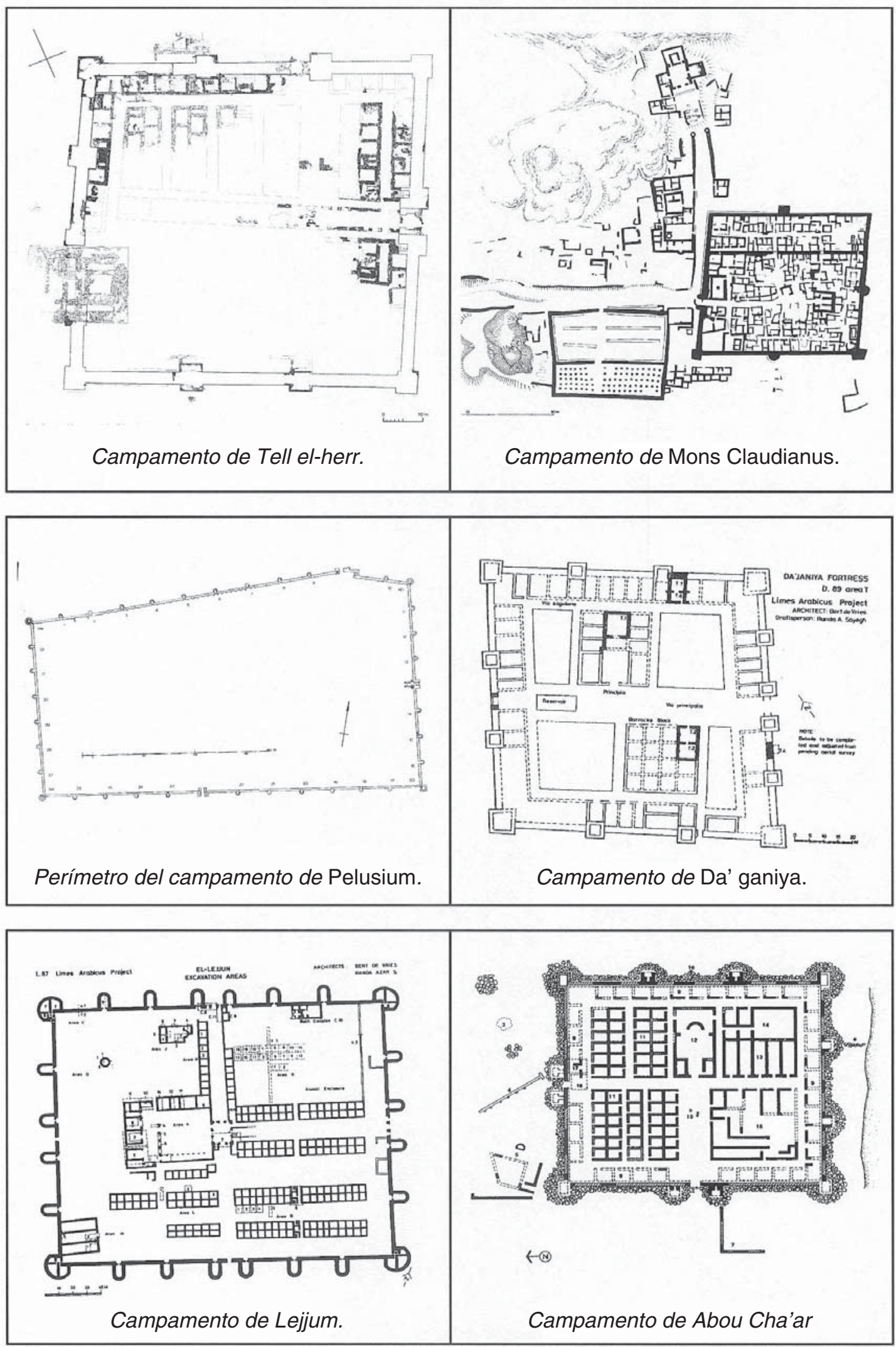


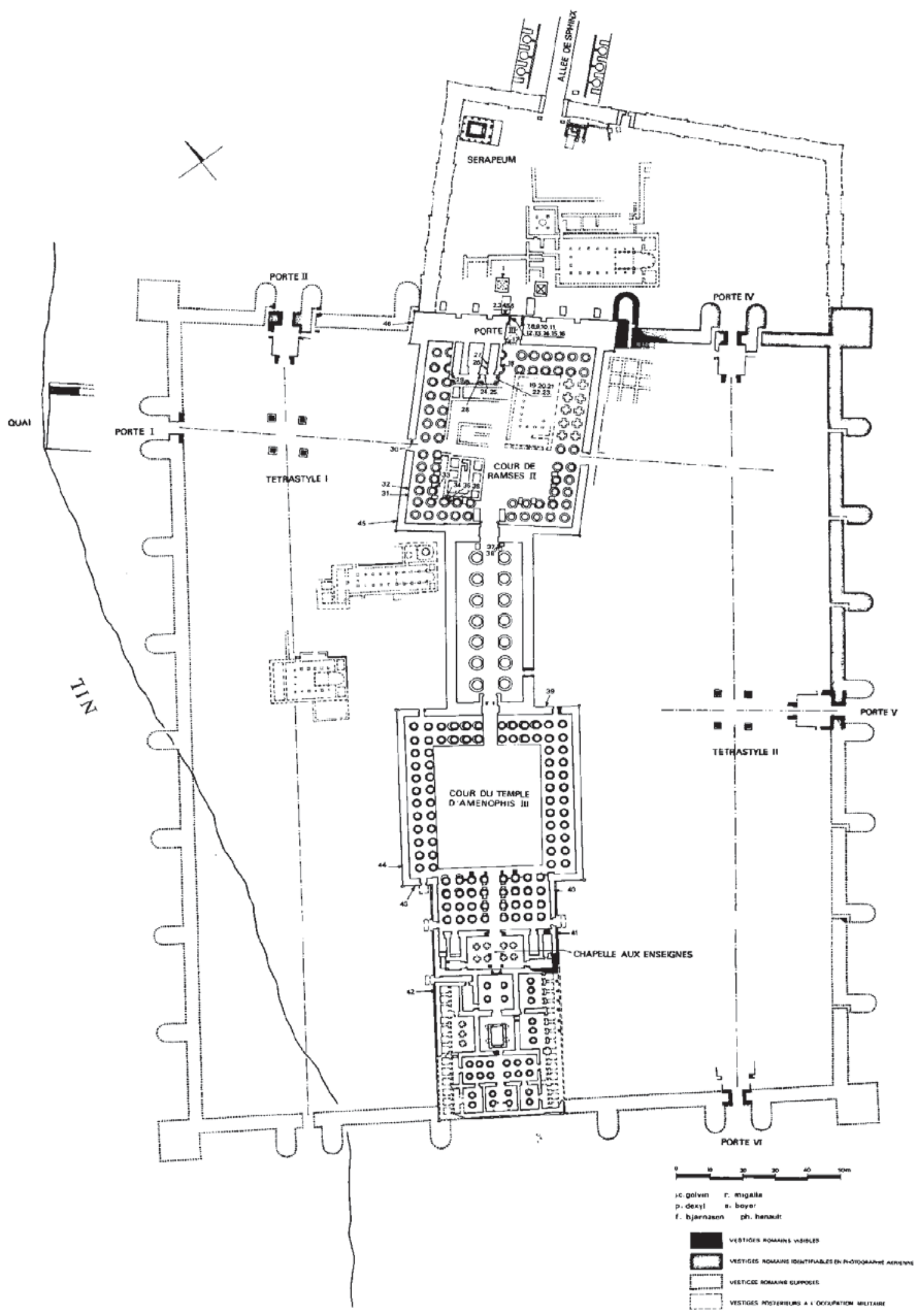

Campamento romano de Luxor, ocupado por la cohorte II Thracum Equitata en 195-1996; y por las legiones I Maximiana y II Flavia Constantia en tiempos de Dioclleciano. 